\title{
Drowsiness or mind-wandering? Fluctuations in ocular parameters during attentional lapses
}

David Stawarczyk $^{1 *}$, Clémentine François ${ }^{2}$, Jérôme Wertz², Arnaud D'Argembeau ${ }^{1,3}$

${ }^{1}$ Department of Psychology, Psychology and Neuroscience of Cognition Research Unit, University of Liège, 4000 Liège, Belgium.

${ }^{2}$ Phasya s.a. Company, 4012 Seraing, Belgium.

${ }^{3}$ GIGA-CRC In Vivo Imaging, University of Liège, 4000 Liège, Belgium.

${ }^{*}$ Correspondence concerning this article should be addressed to David Stawarczyk, Department of Psychology, University of Liège, Quartier Agora, place des Orateurs 1, 4000 Liège 1, Belgium. E-mail: d.stawarczyk@uliege.be. Tel.: 003243665979. 


\begin{abstract}
Two independent lines of evidence suggest that drowsiness and mind-wandering share common neurocognitive processes indexed by ocular parameters (e.g., eyeblink frequency and pupil dynamics). Mind-wandering and drowsiness frequently co-occur, however, such that it remains unclear whether observed oculometric variations are related to mind-wandering, drowsiness, or a mix of both. To address this issue, we assessed fluctuations in mind-wandering and sleepiness during a sustained attention task while ocular parameters were recorded. Results showed that oculometric variations during mind-wandering were fully explained by increased sleepiness. However, mind-wandering and sleepiness had additive deleterious effects on performance that were not fully explained by ocular parameters. These findings suggest that oculometric variations during task performance reflect increased drowsiness rather than processes specifically involved in mind-wandering, and that the neurocognitive processes indexed by oculometric parameters (e.g., regulatory processes of the locus coeruleus norepinephrine system) do not fully explain how mind-wandering and sleepiness cause attentional lapses.
\end{abstract}

Keywords: mind-wandering; pupillometry; eyeblinks; drowsiness; attentional lapses. 


\section{Introduction}

Everyday activities such as driving or attending a lecture require to maintain attentional focus on relevant information over extended periods of time (Engle \& Kane, 2004). Failures in sustaining attention often result in attentional lapses (Broadbent, Cooper, FitzGerald, \& Parkes, 1982; Robertson, Manly, Andrade, Baddeley, \& Yiend, 1997), which can have negative and sometimes dramatic consequences (e.g., driving or railway accidents; Edkins \& Pollock, 1997; Reason, 1984; Warm, 1984). Attentional lapses are frequently linked to the occurrence of taskunrelated thoughts, either in the form of external distractions or mind-wandering episodes (Stawarczyk, Majerus, Maj, Van der Linden, \& D’Argembeau, 2011; Unsworth, Brewer, \& Spillers, 2012; Unsworth, McMillan, Brewer, \& Spillers, 2012). External distractions occur when attention is temporally grasped by sensory experiences that are unrelated to the task at hand (e.g., being distracted while driving because of a smartphone vibrating or because of a sudden urge to sneeze), whereas mind-wandering episodes correspond to a switch of attentional focus from the current task to internally generated thoughts that are decoupled from the here and now, such as memories of past events, personal concerns, or plans about the future (Lustig, Hasher, \& Tonev, 2001; Smallwood \& Schooler, 2015; Stawarczyk et al., 2011; Unsworth \& McMillan, 2014).

Task-unrelated thoughts have been investigated in laboratory tasks and daily life activities by means of a thought-probe method that consists in randomly presenting probes that ask people to report whether they were fully focused on task or whether they were thinking about something else just before being asked (Robison, Miller, \& Unsworth, 2019; Smallwood \& Schooler, 2006; Weinstein, 2018). Studies using this method suggest that mind-wandering and external distractions represent from 30 to $50 \%$ of our daily thinking time (Kane et al., 2007; Killingsworth \& Gilbert, 2010). Although task-unrelated thoughts can have beneficial effects (e.g., the detection of threats 
in the external environment or the elaboration of future plans; Baird, Smallwood, \& Schooler, 2011; Medea et al., 2018; Stawarczyk, 2018; Stawarczyk, Cassol, \& D’Argembeau, 2013), the shift of attention focus away from the task at hand is often associated with decreased task performance (Mooneyham \& Schooler, 2013; Randall, Oswald, \& Beier, 2014). For instance, during the Sustained Attention to Response Tasks (SART; Robertson et al., 1997; Smilek, Carriere, \& Cheyne, 2010a), one of the most commonly used task to assess attentional lapses, mindwandering and external distractions have been consistently associated with lower accuracy and more variable response times (RTs; McVay \& Kane, 2009, 2012; Stawarczyk \& D’Argembeau, 2016; Stawarczyk, Majerus, Catale, \& D’Argembeau, 2014; Stawarczyk et al., 2011). Furthermore, studies using ecological assessments in naturalistic situations have found that taskunrelated thoughts are associated with hazardous driving practices (Baldwin et al., 2017; He, Becic, Lee, \& McCarley, 2011; Lemercier et al., 2014; Pepin et al., 2018; Qu et al., 2015; Yanko \& Spalek, 2014), including road crash responsibility (Galera et al., 2012; Gil-Jardiné et al., 2017), and with decreased memory for information presented during lectures, which may lead to poor academic performance (Farley, Risko, \& Kingstone, 2013; Lindquist \& McLean, 2011; Mrazek, Franklin, Phillips, Baird, \& Schooler, 2013; Wammes, Seli, Cheyne, Boucher, \& Smilek, 2016).

Mind-wandering and external distractions are not the only causes of attentional lapses, with ample evidence showing that sleep-related disturbances also negatively impact attention during the day. Daytime sleepiness corresponds to the tendency to doze off or fall asleep during daily activities, mostly because of a lack of sleep due to inadequate sleep and waking times (Hershner \& Chervin, 2014; Lund, Reider, Whiting, \& Prichard, 2010). Recent epidemiological studies suggest that this phenomenon is particularly frequent in young adults, with sleep disturbances affecting from 15 to $25 \%$ of college students (Buboltz et al., 2009; Ford, Cunningham, Giles, \& 
Croft, 2015; Taylor, Bramoweth, Grieser, Tatum, \& Roane, 2013). Daytime sleepiness and related sleep disturbances have been associated with attentional lapses of similar nature as those induced by task-unrelated thoughts, notably impaired RTs and accuracy during laboratory attention tasks, including the SART (Gobin, Banks, Fins, \& Tartar, 2015; Jackson \& Van Dongen, 2011; Larue, Rakotonirainy, \& Pettitt, 2010; Lim \& Dinges, 2008; Short \& Banks, 2014), an increased risk of driving accidents (Connor et al., 2002; Garbarino, Nobili, Beelke, De Carli, \& Ferrillo, 2001; MacLean, Davies, \& Thiele, 2003), and poorer academic performance (Curcio, Ferrara, \& De Gennaro, 2006; Gaultney, 2010; Gomes, Tavares, \& de Azevedo, 2011).

Interestingly, an increasing body of evidence suggests that task-unrelated thoughts and daytime sleepiness are closely linked. For instance, studies using sleep deprivation procedures have found that a lack of sleep is associated with more frequent reports of task-unrelated thoughts during attentional tasks (Mikulincer, Babkoff, Caspy, \& Weiss, 1990; Poh, Chong, \& Chee, 2016; Schwarz et al., 2017). In addition, several studies have reported a positive correlation between mind-wandering and shorter sleep duration or sleep disturbances, as assessed by self-rated questionnaires (Baker, Baldwin, \& Garner, 2015; Carciofo, Du, Song, \& Zhang, 2014; Ottaviani \& Couyoumdjian, 2013; Shaw et al., 2010; Walker \& Trick, 2018). Finally, research using thought-probes in daily life have found that individuals report being off-task more frequently when they are more tired (Kane et al., 2007, 2017; McVay, Kane, \& Kwapil, 2009). Together, these studies suggest that daytime sleepiness and task-unrelated thoughts frequently co-occur, although the exact nature of the association between these two phenomena remains unclear.

The relations between off-task thinking, daytime sleepiness, and attentional lapses were formally assessed in a recent study by Stawarczyk and D'Argembeau (2016). Fluctuations in daytime sleepiness during the SART were assessed using the Karolinska Sleepiness Scale (KSS, 
a 9-point Likert scale assessing the extent to which individuals are alert and awake; Akerstedt \& Gillberg, 1990) at each thought-probe, along with the assessment of mind-wandering and external distractions (for studies reporting the validity of this procedure to assess daytime sleepiness, see Kaida, Akerstedt, Kecklund, Nilsson, \& Axelsson, 2007; Kaida et al., 2006; Schleicher, Galley, Briest, \& Galley, 2008). As expected, Stawarczyk and D'Argembeau (2016) found that selfreported sleepiness gradually increased with time on task. Furthermore, individual differences in mind-wandering during the task were correlated with sleepiness. Interestingly, sleepiness and mind-wandering were independent predictors of task performance (i.e., both uniquely contributed to attentional lapses). Similar results were found at the within-participant level: task-unrelated thoughts (mind-wandering and external distractions) and sleepiness provided independent contribution to the prediction of attentional lapses. These results suggest that although taskunrelated thoughts and daytime sleepiness tend to co-occur, they are at least partly distinct phenomena that have additive deleterious effects on task performance.

A question that remains is whether task-unrelated thoughts and daytime sleepiness have distinct physiological correlates. Similar fluctuations in ocular parameters have indeed been reported in studies of mind-wandering and in studies of daytime sleepiness. Studies investigating eyelid movements during task performance have found that task-unrelated thoughts are associated with more frequent (Frank, Nara, Zavagnin, Touron, \& Kane, 2015; Grandchamp, Braboszcz, \& Delorme, 2014; Krasich et al., 2018; Smilek, Carriere, \& Cheyne, 2010b) and longer (Grandchamp et al., 2014; Huette, Mathis, \& Graesser, 2016) eyeblinks compared to moments when individuals are fully focused on task. In parallel to these findings, eyeblink frequency and duration are wellknown indicators of daytime sleepiness and fatigue (e.g., Caffier, Erdmann, \& Ullsperger, 2003; He et al., 2017; Körber, Cingel, Zimmermann, \& Bengler, 2015; Schleicher et al., 2008). 
Somewhat surprisingly, however, the increased blink rate and duration observed during taskunrelated thoughts have not been discussed in relation to drowsiness. Instead, changes in these ocular parameters have been attributed to perceptual decoupling: the higher blink rate and longer blink duration during mind-wandering would reflect an isolation process from visual inputs that facilitates the generation and maintenance of internal mentation (Huette et al., 2016; Salvi \& Bowden, 2016; Smilek et al., 2010b). This proposal is supported by findings of increased blink rates and blink duration, as well as attenuated processing of external stimuli, during tasks requiring the generation and manipulation of information that is decoupled from sensory inputs (e.g., creative idea generation; Annerer-Walcher, Körner, \& Benedek, 2018; Benedek, Stoiser, Walcher, \& Körner, 2017; Salvi, Bricolo, Franconeri, Kounios, \& Beeman, 2015; Walcher, Körner, \& Benedek, 2017). However, the extent to which the increased frequency and duration of blinks during mind-wandering reflects perceptual decoupling or drowsiness remains unclear.

Besides eyeblinks, increasing evidence suggests that pupil diameter may also be an indicator of attentional lapses (Hopstaken, van der Linden, Bakker, \& Kompier, 2015b, 2015a; Unsworth \& Robison, 2016; Unsworth, Robison, \& Miller, 2018; van den Brink, Murphy, \& Nieuwenhuis, 2016). During task requiring sustained attention to external stimuli, mind-wandering episodes have been associated with reduced and variable pupil diameters at both the within- and between-individual levels (Faber, Bixler, \& D’Mello, 2018; Grandchamp et al., 2014; Konishi, Brown, Battaglini, \& Smallwood, 2017; Mittner et al., 2014; Unsworth \& Robison, 2017, 2018; but see Franklin, Broadway, Mrazek, Smallwood, \& Schooler, 2013). To the difference of eyelid parameters, these fluctuations in pupil size have been interpreted as a potential marker of fatigue and sleepiness. The reduction in pupil size during task-unrelated thoughts might reflect a tonic hypoactivation of the locus coeruleus norepinephrine system, which is involved in the regulation 
of alertness and arousal, and higher variations in pupil size would reflect difficulties in maintaining a stable level of alertness and arousal over time, thus causing attentional lapses (for a recent review, see Unsworth \& Robison, 2017).

The locus coeruleus is a small nucleus of the brain-stem that is the source of norepinephrine for the cerebral cortex and its activity is closely associated with arousal and circadian rhythm (Berridge \& Waterhouse, 2003; Jouvet, 1969; Samuels \& Szabadi, 2008; Szabadi, 2013). Neural activity within the locus coeruleus positively correlates with pupil size (e.g., Joshi, Li, Kalwani, \& Gold, 2016; Murphy, O’Connell, O’Sullivan, Robertson, \& Balsters, 2014) and it has been shown that optimal task performance is associated with an intermediate activity level of this nucleus, with hypoactivation leading to attentional lapses caused by low alertness and arousal, and hyperactivation leading to task disengagement caused by anxiety and distractibility (Aston-Jones \& Cohen, 2005; Cohen, Aston-Jones, \& Gilzenrat, 2004). Given the close relation between arousal and daytime sleepiness (Bakotić \& Radošević-Vidaček, 2012), it is likely that the reduced and variable pupil diameters that are observed during mind-wandering correspond to increased fatigue and sleepiness. However, to date, no study has assessed pupil parameters in relation to taskunrelated thoughts and daytime sleepiness within the same experimental paradigm. Pupil size being determined by a multitude of physiological and cognitive factors besides arousal and locus coeruleus activity (for recent reviews, see Larsen \& Waters, 2018; Mathot, 2018), it is possible that variables other than sleepiness and alertness are associated with changes in pupil diameter during mind-wandering. For instance, studies that compared ocular parameters during tasks requiring attention to either external stimuli or internal thoughts have found larger pupil diameters for internally directed attention, possibly caused by a higher cognitive workload or attentional effort compared to tasks involving external attention (e.g., Benedek et al., 2017; van der Wel \& 
van Steenbergen, 2018; Walcher et al., 2017). It could thus be that, after controlling for sleepiness, mind-wandering would be associated with increased pupil sizes, reflecting the cognitive demands required to generate and maintain internal thoughts while shielding them from interfering sensory inputs (Smallwood, 2013). This may explain why a minority of studies have found larger rather than smaller pupil sizes in association with mind-wandering (Franklin et al., 2013; for more indirect evidence, see also Smallwood et al., 2012, 2011).

In summary, various ocular parameters (blink frequency, blink duration, mean pupil diameter, and variability of pupil diameter) have been related to task-unrelated thoughts and daytime sleepiness. However, no study to date has attempted to jointly assess these two sources of attentional lapses, such that it remains unclear whether mind-wandering and sleepiness have distinguishable ocular correlates. This is particularly important because there is currently a surge in research using ocular parameters in attempts to develop automated systems that monitor the occurrence of task-unrelated thoughts (e.g., Faber et al., 2018; Gwizdka, 2019; Mittner et al., 2014; Zhao, Lofi, \& Hauff, 2017) or drowsiness (e.g., François, Hoyoux, Langohr, Wertz, \& Verly, 2016; He et al., 2017; Jackson et al., 2016; Rost et al., 2015). However, the ability of these systems to distinguish between drowsiness and task-unrelated thoughts remains unclear. Determining whether some variations in ocular parameters are more sensitive to the occurrence of mindwandering or daytime sleepiness would help further develop these novel detection methods. Furthermore, specifying the ocular correlates of mind-wandering and sleepiness might also help to determine the extent to which their effects on task performance have similar physiological bases.

To address these questions, we asked a group of participants to perform a version of the SART with probes assessing both sleepiness and task-unrelated thoughts, while changes in blink and pupil parameters were recorded using photo-oculography (François et al., 2016). Besides 
replicating the additive effect of task-unrelated thoughts and daytime sleepiness on task performance (Stawarczyk \& D'Argembeau, 2016), our aim was to investigate to what extent fluctuations in ocular parameters during the SART are related to task-unrelated thoughts, sleepiness, or a combination of both. On the one hand, if fluctuations in some ocular parameters during mind-wandering reflect cognitive processes that are specific to this mental state (e.g., perceptual decoupling), then these parameters (i.e., longer and more frequent eyeblinks, and increased pupil diameter) should be associated with mind-wandering even when sleepiness is taken into account. On the other hand, if the changes in ocular parameters that are observed during mindwandering result from increased drowsiness, then mind-wandering should no longer be associated with measures of eyeblinks and pupil size when sleepiness is taken into account. Finally, another aim of the present study was then to assess whether the deleterious effects of sleepiness and mindwandering on task performance depend on neurocognitive processes indexed by ocular parameters (e.g., dysregulations of the locus coeruleus norepinephrine system). If this is the case, the effects of mind-wandering and sleepiness on SART performance should be accounted for by fluctuations in pupil diameter and blink features.

\section{Methods}

The fully anonymized data files and coded data, as well as all the study materials can be obtained from the first author upon request. This study was approved by the Ethics Committee of the Department of Psychology, Speech Therapy, and Education of the University of Liège. Informed consent was obtained from all the participants before the beginning of the study and the methods were carried out in accordance with the relevant guidelines and regulations. We report all measures, manipulations, and data exclusions below, as well as how we determined sample size (Simmons, Nelson, \& Simonsohn, 2011). 


\subsection{Participants}

Thirty-three participants ( 25 women) took part in this study (mean age $=21.76$ years, $S D=2.02$, range $=18-25$ years). All of them were students at the University of Liège, with a mean of 2.70 completed years of higher education $(S D=1.65$, range $=0-6$ years $)$. One additional participant was tested but excluded from the final sample because ocular parameters could not be reliably extracted from the data. Individuals with delayed sleep schedules (e.g., shift workers) or suffering from medical, neurological, or psychiatric disorders were not included in the study. A power analysis computed in R using the SIMR package (Green \& MacLeod, 2016) on the data from our previous experiment using a similar experimental task (Stawarczyk \& D'Argembeau, 2016) revealed that this sample size was sufficient to replicate the within-subject additive effects of thought-probe responses and KSS scores on attentional lapses during the SART (as indexed by accuracy to the target stimuli) with a power of $99.7 \%(95 \%$ CI $[99.13,99.94]$ and alpha value of .05 . The mean subjective sleep duration reported by our participants in the 7 days preceding the testing session was $7.57 \mathrm{hr}(S D=1.17$, range $=5-11 \mathrm{hr})$. This duration is similar to the usual sleep length reported by college students in western countries (Lund et al., 2010) and to the values reported in our previous study with a sample drawn from a similar population (Stawarczyk \& D'Argembeau, 2016). Participants received a monetary compensation of 15 euros for their participation.

\subsection{SART with embedded thought-probes and KSS.}

Participants carried out an adaptation of the SART used in Stawarczyk \& D'Argembeau (2016). Numbers comprised between 1 and 9 were sequentially presented in the center of a laptop computer screen and participants were instructed to respond as fast and accurately as possible to each number (i.e., the non-target stimuli) by pressing the spacebar on the keyboard, except when 
presented with the number 3 (i.e., the target stimulus; $11 \%$ of probability of appearance) for which they were told to withhold their response. Each stimulus was presented in white font (Arial with a point size of 72) on a black background for $500 \mathrm{~ms}$, with an interstimulus interval of 2,000 ms (Smallwood et al., 2004). The task consisted in 30 blocks of either 30, 45, 60, 75 or $90 \mathrm{~s}$. The blocks were randomly presented with the limitation that each set of 5 blocks comprised one block of each length. The last five stimuli of each block were always non-targets and at least one trial per block was a target stimulus. The blocks were immediately followed by the KSS (Akerstedt \& Gillberg, 1990), which interrupted the task and asked participants how they felt right before the interruption. The KSS is a measure of subjective sleepiness that consists in a 9-point Likert scale ranging from 1 (completely alert) to 9 (very sleepy, great effort to keep awake).

Immediately after the KSS, participants were asked to characterize the ongoing conscious experience they had just prior the interruption (Stawarczyk et al., 2011). Five possibilities were provided: (a) on-task: the participant's attention and thoughts were fully focused on the taskrelated stimuli; (b) task-related interference: the participant experienced thoughts about some task features or about their performance (e.g., thoughts about task duration or about the participant's overall performance; participants were explained that this category comprised all thoughts about the task that did not help them to respond as fast and accurately as possible to the numbers presented on the screen); (c) external distraction: the participant's attention was focused on stimuli that were present in the current environment but unrelated to the task at hand (e.g., exteroceptive perceptions or interoceptive sensations; it was explained that this category comprised all thoughts whose content was directly focused on current sensory perceptions unrelated to the task at hand, with the origin of these perceptions being either the surrounding environment or bodily sensations); (d) mind-wandering: the participant had his or her attention decoupled from the 
current environment and was experiencing thoughts unrelated to the task at hand (e.g., thoughts about what the participant will do later in the day $\left.{ }^{1}\right)$; and (e) absence: the participant's attention was not focused on the task at hand and he or she was not thinking about anything in particular, meaning that his or her mind was blank (Ward \& Wegner, 2013). After each thought probe, a short text was displayed on the screen asking participants to press the spacebar to continue the task. As in our previous studies (Stawarczyk \& D’Argembeau, 2016; Stawarczyk et al., 2014, 2011), several examples reflecting each category of experience were provided to the participants and they were asked to classify 10 thoughts in the adequate category before the beginning of the SART. They also carried out two training blocks before starting the complete task.

Three indices of task performance were extracted from the data. The first index was the accuracy of responses to the target stimuli for each block of the task, which is commonly used as a measure of attentional lapses during the SART. In addition, we also extracted the coefficient of variation $(\mathrm{CV})$ of RTs and the mean RT to the non-target stimuli for each block, as several studies have shown that a higher variability of RTs and more impulsive RTs reflect an inadequate (mindless) processing of the task stimuli (e.g., Cheyne, Solman, Carriere, \& Smilek, 2009; McVay \& Kane, 2012; Robertson et al., 1997; Smilek et al., 2010a; Stawarczyk et al., 2011).

\subsection{Ocular parameters}

\footnotetext{
${ }^{1}$ As in our previous studies, it was explained to the participants that their answers should only be based on the content of their thoughts, irrespective of their possible triggers. For instance, if a participant was thinking of their upcoming birthday because the number 4 presented during the task reminded them that it will happen on the fourth of next month, they were instructed to categorize this thought as mind-wandering. Similarly, if a participant was thinking about what kind of sandwich to get after the experiment because they were starting to feel hungry during the task, this would count as mind-wandering. In short, participants were instructed to classify such thoughts as instances of mind-wandering regardless of whether these thoughts were triggered by the task or the current environment.
} 
Ocular parameters were recorded using photo-oculography: participants wore a drowsiness monitoring system (prototype of Drowsimeter R100, from Phasya; François et al., 2016) that consists in a pair of eyeglasses that includes a high-speed camera, an infrared illumination source, and a hot mirror. The system provides the values of several ocular parameters extracted from images of the eye that are linked to the movement of the eyelids (including blinks) and pupil size. Specifically, we used image processing algorithms to precisely extract the positions of both eyelids and the position of the pupil in each image of the eye. We then computed several ocular parameters over a time window that corresponded to the duration of each block of the SART. The positions of the eyelids enabled us to measure the opening of the eye. As the average opening of the eye varies greatly from one individual to another, we computed a baseline for each individual in order to obtain a normalized measure of eye opening. We next computed ocular parameters related to blinks and closures of the eye from this normalized measure. The values for blink frequency and blink duration were extracted for each of the 30 blocks of SART. Finally, we determined the pupil diameter from the position of the pupil in each image using another set of algorithms and then extracted the values for mean pupil diameter and standard deviation of the pupil diameter over the duration of each of the 30 blocks of SART.

\subsection{Procedure}

After completing the informed consent form, participants filled a demographic questionnaire and a series of self-report questionnaires assessing their sleep pattern and attention failures in daily life (details on these questionnaires are reported in the supplementary materials but will not be examined here any further as our sample size was not large enough for individual difference analyses). They were then given the instructions of the SART and carried out the two training blocks. While the instructions were being given, electrodes were placed on the participants' head 
and torso for EEG and ECG recordings (these data are not reported here as they are not relevant to the hypotheses tested in the present paper). Participants then performed the SART with thought probes while wearing the drowsiness monitoring system. After completing the task, they were informed that the experiment was over and were asked to fill a monetary compensation form while the EEG and ECG electrodes were removed. The total duration of the testing session was approximately $75 \mathrm{~min}$ and an experimenter stayed in the testing room with the participant for the whole duration of the experiment.

\section{Results}

The data were analyzed using mixed-effects models with participants as random effects. All the models were fitted using the robustlmm package in R (Koller, 2016) and mind-wandering was used as the reference category in all analyses including the category of experience as predictor. This allowed us not only to compare how ocular parameters differed between mind-wandering and on-task reports but also between mind-wandering and external distractions. Because data were aggregated across blocks of different durations, block length was included in all models as a fixed effect covariate of no interest. The models including KSS scores, thought-probe responses, SART performance, and blink parameters were performed on the 990 blocks of the task nested within the 33 participants. Analyses on pupil parameters were performed on 846 blocks nested within 29 participants as these ocular parameters could not be reliably extracted from all blocks and participants. The effects package (Fox, 2003) was used to estimate the fixed effects for plotting. Finally, the within-correlation matrix between the different ocular parameters was computed in $\mathrm{R}$ using the statsBy function of the psych package (Revelle, 2018).

\subsection{Variations of sleepiness with time on task and thought-probe responses}


To investigate whether sleepiness increased with time on task, we performed a growth curve analysis to assess changes in KSS scores over the 30 thought-probes with second-order orthogonal polynomials (i.e., linear and quadratic terms; Mirman; 2014). As shown in Figure 1a, KSS scores increased with time on task and results showed that both the linear $(b=5.93, S E=0.20, t=29.41$, $p<.001)$ and quadratic term $(b=-0.85, S E=0.20, t=-4.20, p<.001)$ were significant, indicating that the slope modeling the increase in sleepiness during the task was steeper at the beginning than end of the SART. The average increase in sleepiness during the entire task (slightly more than 3 points on the scale) is similar to previous observations (Bonnefond, Doignon-Camus, TouzalinChretien, \& Dufour, 2010; Stawarczyk \& D'Argembeau, 2016).

Regarding thought-probe responses, out of the 990 probes, 297 (30\%) were on-task reports, $293(29.60 \%)$ were task-related interferences, 191 (19.29\%) were external distractions, 165 (16.67\%) were mind-wandering episodes, and 44 (4.44\%) were absence reports. A mixed-effects model was used to examine whether sleepiness (KSS scores) varied as a function of responses to the thought-probes. As shown in Figure 1b, results showed that on-task reports $(b=-1.63, S E=$ $0.16, t=-9.98, p<.001)$, task-related interferences $(b=-0.82, S E=0.16, t=-5.25, p<.001)$, and external distractions $(b=-0.39, S E=0.17, t=-2.24, p=.03)$ were associated with lower KSS scores than mind-wandering, whereas no significant difference was found between mindwandering and absence reports $(b=0.48, S E=0.28, t=1.74, p=.08)$.

\subsection{SART performance as a function of sleepiness and thought-probe responses}

We examined whether SART performance varied as a function of responses to the thought-probes and then added KSS scores to the models to determine whether we could replicate the additive effect of task-unrelated thoughts and sleepiness on task performance. Regarding accuracy to the target stimuli, results showed that on-task reports were associated with higher accuracy than mind- 
wandering $(b=16.36, S E=3.38, t=4.84, p<.001)$; mind-wandering did not differ from taskrelated interferences $(b=1.60, S E=3.27, t=0.49, p=.62)$, external distractions $(b=-0.13, S E=$ $3.59, t=-0.04, p=.97)$, and absence reports $(b=-7.11, S E=5.77, t=-1.23, p=.22$; see Figure 2a). The difference in target accuracy between mind-wandering and on-task reports remained significant when adding KSS scores to the model $(b=9.23, S E=3.46, t=2.67, p=.008)$, and KSS scores were associated with lower target accuracy $(b=-4.34, S E=0.66, t=-6.63, p<.001)$. All the other effects remained non-significant (all $p$ 's $\geq .43$; see Figure 2a).

A similar pattern of results was found for the CV of RTs to the non-target stimuli, with ontask reports being associated with lower RT variability than mind-wandering $(b=-2.45, S E=0.58$, $t=-4.22, p<.001$ ), while no difference was observed between mind-wandering and task-related interferences $(b=-0.57, S E=0.56, t=-1.01, p=.31)$, external distractions $(b=-0.12, S E=0.62$, $t=-0.19, p=.85)$, and absence reports $(b=1.05, S E=0.99, t=1.06, p=.29$; see Figure 2b). When adding KSS scores to the model, the difference in RT variability between mind-wandering and on-task reports remained significant $(b=-1.91, S E=0.61, t=-3.13, p=.002$; see Figure 2b), and higher KSS scores were associated with more variable RTs $(b=0.35, S E=0.12, t=2.96, p=$ .003 ). All the other effects remained non-significant (all $p$ 's $\geq .37$ ).

Finally, with regard to the mean RT to the non-target stimuli, results revealed that mindwandering was associated with faster (i.e., more impulsive or mindless) RTs than on-task reports $(b=9.14, S E=2.72, t=3.36, p<.001)$ and task-related interferences $(b=8.51, S E=2.61, t=$ $3.26, p=.001)$, but did not differ from external distractions $(b=5.11, S E=2.89, t=1.78, p=.08)$ and absences reports $(b=0.75, S E=4.62, t=0.16, p=.87$; see Figure 2c). Adding the KSS scores to the model did not change the significance of the results regarding on-task reports $(b=$ 6.11, $S E=2.84, t=2.15, p=.03)$ and task-related interferences $(b=6.96, S E=2.62, t=2.65, p=$ 
.008), and higher KSS scores were associated with more impulsive RTs to the non-target stimuli $(b=-2.12, S E=0.56, t=-3.83, p<.001)$. Again, all the other effects remained non-significant (all $p$ 's $\geq .13$; see Figure 2c). Together, these results replicate our previous findings showing that, although sleepiness and mind-wandering are related, they have additive deleterious effects on SART performance (Stawarczyk \& D’Argembeau, 2016).

\subsection{Ocular parameters as a function of sleepiness and thought-probe responses}

\subsubsection{Pupil diameter}

Our next aim was to investigate whether the differences in pupil diameter that have been associated with mind-wandering reports in previous studies can be explained by variations in arousal, as proposed by the locus coeruleus norepinephrine account (Unsworth \& Robison, 2017). If arousal level fully explains the variations in pupil diameter associated with mind-wandering, then the differences in mean and standard deviation of pupil diameter between the thought-probe responses should not remain significant once KSS scores are taken into account.

Regarding mean pupil diameter, results showed that mind-wandering was associated with smaller pupil sizes than on-task reports $(b=1.34, S E=0.27, t=5.00, p<.001)$, task-related interferences $(b=0.74, S E=0.26, t=2.84, p=.005)$, and external distractions $(b=0.64, S E=$ $0.28, t=2.26, p=.02)$; there was no difference between mind-wandering and absence reports $(b$ $=-0.21, S E=0.44, t=-0.48, p=.63$; see Figure 3a). However, the differences between mindwandering and on-task reports $(b=0.34, S E=0.26, t=1.26, p=.20)$, task-related interferences $(b$ $=0.20, S E=0.25, t=0.81, p=.42)$, and external distractions $(b=0.23, S E=0.26, t=0.86, p=$ .39) were no longer significant when entering KSS scores in the model; the difference with absence reports remained non-significant $(b=-0.04, S E=0.41, t=-0.11, p=.91$; see Figure 3a). Higher KSS scores were associated with smaller pupil sizes $(b=-0.56, S E=0.05, t=-11.46, p<.001)$. 
Regarding the standard deviation of the pupil diameter, results revealed that mindwandering was associated with a more variable pupil size than on-task reports $(b=-0.22, S E=$ $0.90, t=-2.40, p=.01)$, but did not differ from task-related interferences $(b=-0.05, S E=0.09, t$ $=-0.55, p=.58)$, external distractions $(b=-0.11, S E=0.09, t=-1.20, p=.23)$, and absence reports $(b=0.15, S E=0.15, t=1.03, p=.30$; see Figure 3b). After adding KSS scores to the model, the difference between mind-wandering and on-task reports was no longer significant $(b=-0.09, S E$ $=0.09, t=-1.00, p=.32$ ), while higher KSS scores were associated with more variable pupil size $(b=0.07, S E=0.02, t=4.04, p<.001)$. All the other effects remained non-significant (all $p$ 's $\geq$ .36; see Figure 3b).

Together, these results indicate that the differences in pupil diameter associated with mindwandering are fully explained by changes in daytime sleepiness, in line with the locus coeruleus norepinephrine account of fluctuations in pupil diameter during mind-wandering (Unsworth \& Robison, 2017).

\subsubsection{Blink parameters}

If blinking is specifically involved in the perceptual decoupling aspect of mind-wandering (Huette et al., 2016; Salvi \& Bowden, 2016; Smilek et al., 2010b), then blink frequency and duration should be larger during mind-wandering than when attention is focused on the external environment (i.e., on-task reports and external distractions). Furthermore, mind-wandering should be associated with larger blinking parameters even when sleepiness is taken into account.

Regarding blink frequency, results showed that mind-wandering was associated with more frequent eyeblinks than on-task reports $(b=-0.04, S E=0.01, t=-3.43, p<.001)$ and task-related interferences $(b=-0.02, S E=0.01, t=-2.04, p=.04)$. There was no difference between mindwandering and external distractions $(b=-0.01, S E=0.01, t=-0.92, p=.36)$ or absence reports $(b$ 
$=-0.01, S E=0.02, t=-0.80, p=.42$; see Figure 4a). The difference between mind-wandering and on-task reports $(b=-0.02, S E=0.01, t=-1.72, p=.09)$ and task-related interferences $(b=-0.01$, $S E=0.01, t=-1.07, p=.28$ ) was no longer significant after adding KSS scores to the model, and higher KSS scores were related to more frequent blinks ( $b=0.01, S E=0.002, t=4.68, p<.001)$. All the other effects remained non-significant (all $p$ 's $\geq .30$; see Figure 4a).

In terms of blink duration, results showed that mind-wandering was associated with longer blinks than on-task reports $(b=-7.21, S E=2.58, t=-2.80, p=.005)$ but no difference was found with the other thought-probe responses: task-related interferences $(b=-4.05, S E=2.47, t=-1.64$, $p=.10)$, external distractions $(b=-2.58, S E=2.71, t=-0.95, p=.34)$, and absences $(b=5.15, S E$ $=3.37, t=1.18, p=.24$; see Figure $\mathbf{4 b}$ ). When adding KSS score to the model, the difference between mind-wandering and on-task reports became non-significant $(b=-2.34, S E=2.70, t=-$ $0.87, p=.38)$, and higher KSS scores were associated with longer blinks $(b=-3.34, S E=0.53, t$ $=6.36, p<.001$ ). All the other effects remained non-significant (all $p$ 's $\geq .36$; see Figure $4 \mathbf{b}$ ).

Together, these results do not support the view that blinks during mind-wandering reflect perceptual decoupling (Huette et al., 2016; Salvi \& Bowden, 2016; Smilek et al., 2010b). First, the frequency and duration of blinks did not differ between mind-wandering and external distractions. Second, the difference between mind-wandering and on-task reports were fully explained by the KSS scores, suggesting that changes in blink parameters associated with mind-wandering are due to increased sleepiness rather than perceptual decoupling per se.

\subsection{Can the effects of mind-wandering and sleepiness on task performance be accounted for by} the neurocognitive processes indexed by ocular parameters?

Finally, we sought to investigate whether the effects of mind-wandering and sleepiness on SART performance can be accounted for by variations in ocular parameters. To do so, we first performed 
mixed-effects analyses to determine whether the ocular parameters were associated with SART performance in the expected directions. As the four ocular parameters were only weakly correlated (see Table S2), we included all four measures together as predictors in the models ${ }^{2}$, with indices of SART performance as dependent variable. We then computed models with the ocular parameters, KSS scores and thought probe-responses as fixed effects to examine whether the additive effect of mind-wandering and sleepiness on task performance remained significant.

For accuracy to the target stimuli, the analyses with the ocular parameters as fixed effects showed that higher blink frequency $(b=-17.53, S E=6.44, t=-2.72, p=.007)$ and longer blink duration $(b=-0.09, S E=0.03, t=-3.28, p=.001)$ were both associated with lower accuracy. No significant relationships were found for mean pupil diameter $(b=0.03, S E=0.25, t=0.12, p=$ $.90)$ or the standard deviation of pupil diameter $(b=1.26, S E=1.11, t=0.91, p=.26)$. For the CV of RTs to the non-targets, higher blink frequency $(b=3.05, S E=1.18, t=2.59, p=.01)$, longer blink duration $(b=0.014, S E=0.005, t=2.79, p=.005)$, and a smaller pupil diameter $(b=-0.14$, $S E=0.05, t=2.79, p=.005)$ were all associated with more variable RTs. No significant effect was found for the variability of pupil diameter $(b=0.19, S E=0.20, t=0.93, p=.35)$. Finally, for the mean RT to non-target stimuli, only blink duration $(b=-0.06, S E=0.03, t=-2.53, p=.01)$ was associated with shorter (i.e., impulsive or mindless) RTs; no significant effect was found for blink frequency $(b=-7.14, S E=5.91, t=-2.53, p=.23)$, mean pupil diameter $(b=0.23, S E=$

\footnotetext{
${ }^{2}$ To account for the proposal that both low and high pupil diameter might cause attentional lapses due to respectively hypo- and hyperactivation of the locus coeruleus norepinephrine system (Aston-Jones \& Cohen, 2005; Berridge \& Waterhouse, 2003), we also computed models with the addition of a quadratic term for mean pupil diameter. This quadratic term was not significant in any of the models and we thus only report here the simpler analyses where mean pupil diameter was modeled with a single linear regressor.
} 
$0.29, t=0.82, p=.41)$, and standard deviation of the pupil diameter $(b=1.50, S E=0.99, t=1.51$, $p=.13)$.

Given that the ocular parameters were overall associated with task performance in the expected directions, we investigated whether these ocular parameters accounted for the effects of sleepiness and mind-wandering on SART performance. Regarding accuracy to the target stimuli, we found that the effects of mind-wandering and sleepiness remained significant when ocular parameters were taken into account. More specifically, on-task reports $(b=9.24, S E=3.78, t=$ 2.44, $p=.01)$ were still associated with higher accuracy than mind-wandering, and KSS scores were still associated with decreased accuracy $(b=-4.17, S E=0.70, t=-5.97, p<.001)$. In this model, higher blink frequency was also still associated with lower target accuracy $(b=-13.31, S E$ $=6.28, t=-2.12, p=.03$ ) and the standard deviation of the pupil diameter became significantly associated with accuracy $(b=2.22, S E=1.08, t=2.06, p=.04)$, suggesting that, after controlling for sleepiness and thought-probe responses, more variations in pupil diameter are associated with fewer attentional lapses. All other effects were non-significant (all $p \mathrm{~s} \geq .25$ ). The effects of mindwandering and sleepiness on the CV of RTs to the non-target stimuli also remained significant when ocular parameters were taken into account, with RTs being less variable for on-task reports than mind-wandering $(b=-2.24, S E=0.69, t=3.26, p=.001)$ and more variable with higher KSS scores $(b=0.28, S E=0.12, t=2.22, p=.03)$. Blink frequency $(b=2.56, S E=1.16, t=2.21, p=$ $.03)$ and pupil diameter $(b=-0.10, S E=0.05, t=2.79, p=.047)$ also remained associated with task performance. All other effects were not significant (all $p s \geq .08$ ). Finally, for the mean RT to non-target stimuli, the differences between mind-wandering and on-task reports $(b=4.60, S E=$ 3.27, $t=1.41, p=.16)$ and task-related interferences $(b=5.03, S E=3.05, t=1.65, p=.10)$ were no longer significant when ocular parameters were entered in the model. However, higher KSS 
scores remained associated with shorter (more impulsive) RTs $(b=-2.14, S E=0.63, t=3.34, p<$ .001). All other effects were non-significant (all $p \mathrm{~s} \geq .07$ ).

Together these results indicate that the deleterious effects of sleepiness and mindwandering reports on task performance cannot be fully explained in terms of the neurocognitive processes indexed by fluctuations in pupil diameters and eyeblink features.

\section{Discussion}

Recent research suggests that several ocular parameters (pupil diameter, blink frequency, and blink duration) are sensitive to increased drowsiness and the occurrence of task-unrelated thoughts. However, it remains unclear whether these two sources of attentional lapses have distinguishable ocular correlates and affect task performance through similar neurocognitive processes. This issue is particularly important as two distinct streams of research using oculography are currently attempting to develop drowsiness and mind-wandering monitoring systems, with the aim of preventing attentional lapses in real life situations. So far, the extent to which these monitoring systems capture attentional fluctuations specifically caused by either drowsiness or task-unrelated thoughts is equivocal. To shed light on this issue, we used a version of the SART with probes that assessed both the occurrence of task-unrelated thoughts and sleepiness, while fluctuations in participants' pupil diameter and blink features were recorded.

In line with previous studies (e.g., Bonnefond et al., 2010; Schneider et al., 2008; Stawarczyk \& D’Argembeau, 2016), we found that sleepiness gradually increased with time on task and that the occurrence of mind-wandering was related to sleepiness. Considering this relation between mind-wandering and sleepiness, our goal was then to examine whether these two sources of attentional lapses are associated with distinct ocular parameters. Our results showed that the four ocular parameters investigated here were associated with mind-wandering in the expected 
direction: blinks were longer and more frequent, and pupil diameter showed a reduced a more variable size in task blocks that were associated with mind-wandering than in blocks where participants reported being fully focused on the task (see also, Grandchamp et al., 2014; Huette et al., 2016; Smilek et al., 2010b; Unsworth \& Robison, 2017). Most importantly, however, the inclusion of KSS scores in addition to thought-probe responses in the regression models indicated that sleepiness significantly predicted changes in all ocular parameters and that the differences between mind-wandering and on-task reports were no longer significant when sleepiness was taken into account. These results suggest that fluctuations in ocular parameters with task-unrelated thoughts mostly result from increased drowsiness rather than processes specifically associated with mind-wandering per $s e^{3}$.

These findings have important implications for understanding the basis of fluctuations in ocular parameters that are observed during mind-wandering. Previous accounts have suggested that higher blink rates and duration during off-task thoughts reflect perceptual decoupling (i.e., an isolation process from sensory inputs that facilitates the generation and maintenance of internal thoughts; Huette et al., 2016; Salvi \& Bowden, 2016; Schooler et al., 2011; Smilek et al., 2010b). The present results showing that the higher frequency and duration of eyeblinks during mindwandering was fully accounted for by sleepiness do not support this proposal. Furthermore, according to the perceptual decoupling account, mind-wandering should be associated with more frequent and longer blinks than both on-task reports and external distractions, as these two types of experiences reflect an attentional focus on current sensory inputs (Stawarczyk et al., 2014, 2011;

\footnotetext{
${ }^{3}$ Note that the relation between mind-wandering and ocular parameters might differ in situations that involve high levels of arousal. Indeed, preliminary evidence suggests that when arousal is excessive (e.g., following stress induction procedures), mind-wandering might be associated with increases in pupil size (Unsworth \& Robison, 2018).
} 
Unsworth \& McMillan, 2014). However, we found that mind-wandering did not differ from external distractions in terms of blink features. Therefore, it seems that the longer and more frequent blinks that are observed during task-unrelated thoughts are physiological markers of difficulties to stay focused on task (lower arousal and alertness) rather than a perceptual decoupling process that facilitates the generation and maintenance of internal thoughts.

Increases in blink rates and duration with higher drowsiness may reflect a loosening of cognitive control processes that help maintain attentional focus on the task at hand while filtering out irrelevant information that is internally generated (i.e., mind-wandering) or perceived by sensory organs (i.e., external distractions; Lustig et al., 2001). In line with this view, there is evidence that more frequent eye blinks reflect (at least in part) a dysregulation of the dopaminergic system, whose receptors in the prefrontal cortex and striatum respectively support the active maintenance of task-relevant information and gating mechanisms that prevent interference from distracting stimuli (for reviews, see Cools \& D’Esposito, 2011; Jongkees \& Colzato, 2016; Robbins \& Arnsten, 2009). Evidence in favor of this attention control account notably comes from studies showing that the occurrence of blinks corresponds to moments when attentional control is relaxed while watching video stories (e.g., at the end of an action or when the same scene is repeated; Nakano, Yamamoto, Kitajo, Takahashi, \& Kitazawa, 2009) and increases when performing low demand tasks (e.g., Lean \& Shan, 2012; Maffei \& Angrilli, 2018). In addition, more frequent eye blinks have been related to increased distractibility by irrelevant stimuli in switching tasks (e.g., Dreisbach et al., 2005; Müller et al., 2007; Tharp \& Pickering, 2011). The increased blink rate found in the present study in relation with sleepiness might thus result from a less efficient regulation of attentional control processes supported by the dopaminergic system in the striatum and prefrontal cortex. Although this proposal fits well with neuroimaging studies 
showing dopaminergic dysregulations in these brain areas during sleep deprivation (e.g., Krause et al., 2017; Volkow et al., 2009), it should be noted that eyeblinks are modulated by a large variety of factors, among which the most obvious is probably the need to rehydrate the eye surface (for a review, see Cruz, Garcia, Pinto, \& Cechetti, 2011). Further studies should therefore be conducted to further assess this dopaminergic account, especially regarding the duration of blinks where evidence is much scarcer.

The view that fluctuations in ocular parameters associated with off-task thoughts reflect a decreased neuromodulation of attention control processes is also concordant with our findings regarding pupil diameter. Specifically, we found that mind-wandering was associated with smaller and more variable pupil diameters than on-task reports and that these differences in pupil size were fully accounted for by increased sleepiness. These results are consistent with the view that the small pupil diameters observed during mind-wandering episodes reflect an hypoactivation of the locus coeruleus norepinephrine system (resulting in attentional lapses due to low alertness and arousal), and that the higher variability of pupil diameter indicates difficulties in maintaining an optimal level of alertness during the task (Unsworth \& Robison, 2017). At the neural level, smaller and more variable pupil diameters might reflect reduced mobilization of fronto-parietal cortical areas involved in attentional control and moment-to-moment task engagement (Spreng, Stevens, Chamberlain, Gilmore, \& Schacter, 2010; Vincent, Kahn, Snyder, Raichle, \& Buckner, 2008) by the locus coeruleus norepinephrine system. By evaluating variations in self-reported sleepiness during the task, our study provides the first direct evidence that pupil diameter fluctuations during mind-wandering are fully explained by increased drowsiness.

We also examined the effects of task-unrelated thoughts and daytime sleepiness on SART performance, as well as the physiological bases of these effects as indexed by ocular parameters. 
The results first replicated the additive deleterious effects of mind-wandering and sleepiness on task performance (target accuracy as well as CV and mean of RTs to the non-target stimuli) observed in our previous study (Stawarczyk \& D'Argembeau, 2016). Intriguingly, however, we found that these effects remained significant after variations in ocular parameters had been taken into account, with the exception of the faster (i.e., more impulsive or mindless) RTs associated with mind-wandering. These results suggest that the deleterious effects of mind-wandering and sleepiness on task performance rely (at least in part) on neurocognitive processes other than those indexed by the ocular parameters investigated here (i.e., dysregulation of the dopaminergic and norepinephrine systems; see above). Neuroimaging studies of sleep deprivation have indeed shown that increased sleep pressure affects a variety of brain functions that extend beyond those directly related to dopamine and norepinephrine systems (for reviews, see Goel, Basner, Rao, \& Dinges, 2013; Goel, Rao, Durmer, \& Dinges, 2009; Krause et al., 2017). Regarding mind-wandering, a recent computational neuroimaging study has revealed that brain activity and ocular parameters both uniquely contribute to classifier performance when attempting to predict thought-probe responses (Mittner et al., 2014). Combining neuroimaging with oculography might thus shed additional light on the psychophysiological processes by which mind-wandering and drowsiness cause attentional lapses. More generally, the present results suggest that including repeated subjective reports of sleepiness in experimental paradigms might prove particularly useful to more comprehensively assess the extent to which drowsiness affects performance over time (for a similar discussion, see Hopstaken et al., 2015b, 2015a).

Although our results do not support the view that eye blinks (and to a lesser extent variations in pupil size) reflect perceptual decoupling, it is important to note that they do not discredit the perceptual decoupling theory altogether (Smallwood, 2013). In particular, perceptual 
decoupling might explain why mind-wandering was related to attentional lapses even when the effects of sleepiness, pupil size, and eyeblink features were taken into account. Future studies should be conducted to determine whether some physiological measures can specifically index the occurrence of perceptual decoupling during mind-wandering. For instance, numerous EEG studies have shown that a variety of event-related potentials (ERP) associated with sensory processing (such as the early $\mathrm{P} 1$ and $\mathrm{N} 1$ components that originate from primary sensory areas or the P300 that index the depth of cognitive processing devoted to task-relevant stimuli) are disrupted during mind-wandering (for reviews, see Handy \& Kam, 2015; Martinon, Smallwood, McGann, Hamilton, \& Riby, 2019). It would be interesting to investigate whether disruptions in these ERP components are specifically related to mind-wandering or whether they can be accounted for by increased sleepiness, as it is the case for blink parameters and pupil size in this study.

In conclusion, the main finding of the present study is that fluctuations in blink duration, blink frequency, mean pupil diameter, and standard deviation of pupil diameter during task performance are better explained by difficulties in maintaining on-task focus due to increased drowsiness rather than processes specifically associated with mind-wandering. These results support the locus coeruleus norepinephrine account of mind-wandering and suggest that variations in blink parameters during mind-wandering are not due to perceptual decoupling processes but may instead reflect a dysregulation in the striato-prefrontal dopaminergic system supporting attentional control processes during task performance. However, the effects of mind-wandering and sleepiness on task performance were not fully accounted for by fluctuations in these ocular parameters, suggesting that the physiological processes linking mind-wandering and drowsiness to behavioral lapses extend beyond those investigated here. An important implication of these findings is that oculography studies aiming at developing mind-wandering monitoring systems 
(e.g., Faber et al., 2018; Gwizdka, 2019; Mittner et al., 2014; Zhao et al., 2017) might be currently more sensitive to the increased drowsiness that is concomitant to the occurrence of off-task thoughts rather than mind-wandering per se. Further studies should be conducted to determine if the occurrence of mind-wandering and sleepiness can be distinguished on the basis of other physiological markers. 


\section{Acknowledgment}

Arnaud D'Argembeau and David Stawarczyk are, respectively, Senior Research Associate and Postdoctoral Researcher of the Fonds de la Recherche Scientifique (F.R.S.-FNRS). David Stawarczyk is currently supported by the European Union's Horizon 2020 Research and Innovation Programme under grant agreement no 798109. We would like to thank Thomas Langhor for his help in collecting the data and developing the study material. D. Stawarczyk, C. François, J. Wertz, and A. D'Argembeau developed the study concept and contributed to the study design. Testing and data collection were performed by D. Stawarczyk and C. François. C. François extracted the data from the eye image recordings. D. Stawarczyk performed the data analysis and interpretation under the supervision of A. D'Argembeau. D. Stawarczyk drafted the manuscript and prepared the figures, and A. D'Argembeau provided critical revisions. All authors approved the final version of the manuscript for submission. The authors declare no competing interest.

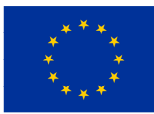




\section{References}

Akerstedt, T., \& Gillberg, M. (1990). Subjective and objective sleepiness in the active individual. International Journal of Neuroscience, 52(1-2), 29-37. https://doi.org/10.3109/00207459008994241

Annerer-Walcher, S., Körner, C., \& Benedek, M. (2018). Eye behavior does not adapt to expected visual distraction during internally directed cognition. PLOS ONE, 13(9), e0204963. https://doi.org/10.1371/journal.pone.0204963

Aston-Jones, G., \& Cohen, J. D. (2005). AN INTEGRATIVE THEORY OF LOCUS COERULEUS-NOREPINEPHRINE FUNCTION: Adaptive Gain and Optimal Performance. Annual Review of Neuroscience, 28(1), 403-450. https://doi.org/10.1146/annurev.neuro.28.061604.135709

Baird, B., Smallwood, J., \& Schooler, J. W. (2011). Back to the future: Autobiographical planning and the functionality of mind-wandering. Consciousness \& Cognition, 20(4), 1604-1611. https://doi.org/10.1016/j.concog.2011.08.007

Baker, L. D., Baldwin, D. S., \& Garner, M. (2015). Daytime intrusive thoughts and subjective insomnia symptoms. Psychiatry Research, 229(3), 1038-1042. https://doi.org/10.1016/j.psychres.2015.02.022

Bakotić, M., \& Radošević-Vidaček, B. (2012). Regulation of sleepiness: the role of the arousal system. Arhiv Za Higijenu Rada I Toksikologiju, 63 Suppl 1, 23-34. https://doi.org/10.2478/10004-1254-63-2012-2137

Baldwin, C. L., Roberts, D. M., Barragan, D., Lee, J. D., Lerner, N., \& Higgins, J. S. (2017). Detecting and Quantifying Mind Wandering during Simulated Driving. Frontiers in Human Neuroscience, 11. https://doi.org/10.3389/fnhum.2017.00406

Benedek, M., Stoiser, R., Walcher, S., \& Körner, C. (2017). Eye Behavior Associated with Internally versus Externally Directed Cognition. Frontiers in Psychology, 8. https://doi.org/10.3389/fpsyg.2017.01092

Berridge, C. W., \& Waterhouse, B. D. (2003). The locus coeruleus-noradrenergic system: modulation of behavioral state and state-dependent cognitive processes. Brain Research Reviews, 42(1), 33-84. https://doi.org/10.1016/S0165-0173(03)00143-7 
Bonnefond, A., Doignon-Camus, N., Touzalin-Chretien, P., \& Dufour, A. (2010). Vigilance and intrinsic maintenance of alert state: An ERP study. Behavioural Brain Research, 211(2), 185-190. https://doi.org/10.1016/j.bbr.2010.03.030

Broadbent, D. E., Cooper, P., FitzGerald, P., \& Parkes, K. R. (1982). The Cognitive Failures Questionnaire (CFQ) and its correlates. British Journal of Clinical Psychology, 21(1), 116. Retrieved from PsycINFO. (1982-24745-001)

Buboltz, W., Jenkins, S. M., Soper, B., Woller, K., Johnson, P., \& Faes, T. (2009). Sleep Habits and Patterns of College Students: An Expanded Study. Journal of College Counseling, 12(2), 113-124. https://doi.org/10.1002/j.2161-1882.2009.tb00109.x

Caffier, P. P., Erdmann, U., \& Ullsperger, P. (2003). Experimental evaluation of eye-blink parameters as a drowsiness measure. European Journal of Applied Physiology, 89(3), 319325. https://doi.org/10.1007/s00421-003-0807-5

Carciofo, R., Du, F., Song, N., \& Zhang, K. (2014). Mind wandering, sleep quality, affect and chronotype: an exploratory study. PLoS ONE [Electronic Resource], 9(3), e91285. https://doi.org/10.1371/journal.pone.0091285

Cheyne, J. A., Solman, G. J. F., Carriere, J. S. A., \& Smilek, D. (2009). Anatomy of an error: A bidirectional state model of task engagement/disengagement and attention-related errors. Cognition, 111(1), 98-113. https://doi.org/10.1016/j.cognition.2008.12.009

Cohen, J. D., Aston-Jones, G., \& Gilzenrat, M. S. (2004). A systems-level perspective on attention and cognitive control: Guided activation, adaptive gating, conflict monitoring, and exploitation vs. exploration. In M. I. Posner (Ed.), Cognitive neuroscience of attention (pp. 71-90). New York: Guilford Press.

Connor, J., Norton, R., Ameratunga, S., Robinson, E., Civil, I., Dunn, R., ... Jackson, R. (2002). Driver sleepiness and risk of serious injury to car occupants: population based case control study. BMJ, 324(7346), 1125. https://doi.org/10.1136/bmj.324.7346.1125

Cools, R., \& D’Esposito, M. (2011). Inverted-U-Shaped Dopamine Actions on Human Working Memory and Cognitive Control. Biological Psychiatry, 69(12), e113-e125. https://doi.org/10.1016/j.biopsych.2011.03.028 
Cruz, A. A. V., Garcia, D. M., Pinto, C. T., \& Cechetti, S. P. (2011). Spontaneous Eyeblink Activity. The Ocular Surface, 9(1), 29-41. https://doi.org/10.1016/S1542-0124(11)700076

Curcio, G., Ferrara, M., \& De Gennaro, L. (2006). Sleep loss, learning capacity and academic performance. Sleep Medicine Reviews, 10(5), 323-337. https://doi.org/10.1016/j.smrv.2005.11.001

Dreisbach, G., Müller, J., Goschke, T., Strobel, A., Schulze, K., Lesch, K.-P., \& Brocke, B. (2005). Dopamine and Cognitive Control: The Influence of Spontaneous Eyeblink Rate and Dopamine Gene Polymorphisms on Perseveration and Distractibility. Behavioral Neuroscience, 119(2), 483-490. https://doi.org/10.1037/0735-7044.119.2.483

Edkins, G. D., \& Pollock, C. M. (1997). The influence of sustained attention on Railway accidents. Accident Analysis \& Prevention, 29(4), 533-539. https://doi.org/10.1016/S00014575(97)00033-X

Engle, R. W., \& Kane, M. J. (2004). Executive Attention, Working Memory Capacity, and a TwoFactor Theory of Cognitive Control. In B. H. Ross (Ed.), The psychology of learning and motivation: Advances in research and theory, Vol 44 (pp. 145-199). https://doi.org/10.1016/S0079-7421(03)44005-X

Faber, M., Bixler, R., \& D’Mello, S. K. (2018). An automated behavioral measure of mind wandering during computerized reading. Behavior Research Methods, 50(1), 134-150. https://doi.org/10.3758/s13428-017-0857-y

Farley, J., Risko, E. F., \& Kingstone, A. (2013). Everyday attention and lecture retention: the effects of time, fidgeting, and mind wandering. Frontiers in Psychology, 4, 619. https://doi.org/10.3389/fpsyg.2013.00619

Ford, E. S., Cunningham, T. J., Giles, W. H., \& Croft, J. B. (2015). Trends in insomnia and excessive daytime sleepiness among U.S. adults from 2002 to 2012. Sleep Medicine, 16(3), 372-378. https://doi.org/10.1016/j.sleep.2014.12.008

Fox, J. (2003). Effect Displays in R for Generalised Linear Models. Journal of Statistical Software, $8(15), 1-27$. 
François, C., Hoyoux, T., Langohr, T., Wertz, J., \& Verly, J. G. (2016). Tests of a New Drowsiness Characterization and Monitoring System Based on Ocular Parameters. International Journal of Environmental Research \& Public Health [Electronic Resource], 13(2). https://doi.org/10.3390/ijerph13020174

Frank, D. J., Nara, B., Zavagnin, M., Touron, D. R., \& Kane, M. J. (2015). Validating older adults' reports of less mind-wandering: An examination of eye movements and dispositional influences. Psychology \& Aging, 30(2), 266-278. https://doi.org/10.1037/pag0000031

Franklin, M. S., Broadway, J. M., Mrazek, M. D., Smallwood, J., \& Schooler, J. W. (2013). Window to the wandering mind: Pupillometry of spontaneous thought while reading. Quarterly Journal of Experimental Psychology, 66(12), 2289-2294. https://doi.org/10.1080/17470218.2013.858170

Galera, C., Orriols, L., M'Bailara, K., Laborey, M., Contrand, B., Ribereau-Gayon, R., ... Lagarde, E. (2012). Mind wandering and driving: responsibility case-control study. BMJ, 345, e8105. https://doi.org/10.1136/bmj.e8105

Garbarino, S., Nobili, L., Beelke, M., De Carli, F., \& Ferrillo, F. (2001). The contributing role of sleepiness in highway vehicle accidents. Sleep: Journal of Sleep Research \& Sleep Medicine, 24(2), 203-206. Retrieved from PsycINFO. (2001-00400-006)

Gaultney, J. F. (2010). The prevalence of sleep disorders in college students: impact on academic performance. Journal of American College Health, 59(2), 91-97. https://doi.org/10.1080/07448481.2010.483708

Gil-Jardiné, C., Née, M., Lagarde, E., Schooler, J., Contrand, B., Orriols, L., \& Galera, C. (2017). The distracted mind on the wheel: Overall propensity to mind wandering is associated with road crash responsibility. PLOS ONE, 12(8), e0181327. https://doi.org/10.1371/journal.pone.0181327

Gobin, C. M., Banks, J. B., Fins, A. I., \& Tartar, J. L. (2015). Poor sleep quality is associated with a negative cognitive bias and decreased sustained attention. Journal of Sleep Research, 24(5), 535-542. https://doi.org/10.1111/jsr.12302 
Goel, N., Basner, M., Rao, H., \& Dinges, D. F. (2013). Circadian Rhythms, Sleep Deprivation, and Human Performance. Progress in Molecular Biology and Translational Science, 119, 155-190. https://doi.org/10.1016/B978-0-12-396971-2.00007-5

Goel, N., Rao, H., Durmer, J. S., \& Dinges, D. F. (2009). Neurocognitive Consequences of Sleep Deprivation. Seminars in Neurology, 29(04), 320-339. https://doi.org/10.1055/s-00291237117

Gomes, A. A., Tavares, J., \& de Azevedo, M. H. (2011). Sleep and academic performance in undergraduates: a multi-measure, multi-predictor approach. Chronobiology International, 28(9), 786-801. https://doi.org/10.3109/07420528.2011.606518

Grandchamp, R., Braboszcz, C., \& Delorme, A. (2014). Oculometric variations during mind wandering. Frontiers in Psychology, 5, 31. https://doi.org/10.3389/fpsyg.2014.00031

Green, P., \& MacLeod, C. J. (2016). SIMR: an R package for power analysis of generalized linear mixed models by simulation. Methods in Ecology and Evolution, 7(4), 493-498. https://doi.org/10.1111/2041-210X.12504

Gwizdka, J. (2019). Exploring Eye-Tracking Data for Detection of Mind-Wandering on Web Tasks. In F. D. Davis, R. Riedl, J. vom Brocke, P.-M. Léger, \& A. B. Randolph (Eds.), Information Systems and Neuroscience (pp. 47-55). Springer International Publishing.

Handy, T. C., \& Kam, J. W. (2015). Mind wandering and selective attention to the external world. Canadian Journal of Experimental Psychology, 69(2), 183-189. https://doi.org/10.1037/cep0000051

He, J., Becic, E., Lee, Y.-C., \& McCarley, J. S. (2011). Mind wandering behind the wheel: performance and oculomotor correlates. Human Factors, 53(1), 13-21. https://doi.org/10.1177/0018720810391530

He, J., Choi, W., Yang, Y., Lu, J., Wu, X., \& Peng, K. (2017). Detection of driver drowsiness using wearable devices: A feasibility study of the proximity sensor. Applied Ergonomics, 65, 473-480. https://doi.org/10.1016/j.apergo.2017.02.016

Hershner, S. D., \& Chervin, R. D. (2014). Causes and consequences of sleepiness among college students. Nature \& Science of Sleep, 6, 73-84. https://doi.org/10.2147/NSS.S62907 
Hopstaken, J. F., van der Linden, D., Bakker, A. B., \& Kompier, M. A. J. (2015a). A multifaceted investigation of the link between mental fatigue and task disengagement. Psychophysiology, 52(3), 305-315. https://doi.org/10.1111/psyp.12339

Hopstaken, J. F., van der Linden, D., Bakker, A. B., \& Kompier, M. A. J. (2015b). The window of my eyes: Task disengagement and mental fatigue covary with pupil dynamics. Biological Psychology, 110, 100-106. https://doi.org/10.1016/j.biopsycho.2015.06.013

Huette, H., Mathis, A., \& Graesser, A. (2016). Blink durations reflect mind wandering during reading. In A. Papafragou, D. Grodner, D. Mirman, \& J. C. Trueswell (Eds.), Proceedings of the 38th Annual Conference of the Cognitive Science Society. Austin, TX: Cognitive Science Society.

Jackson, M. L., Kennedy, G. A., Clarke, C., Gullo, M., Swann, P., Downey, L. A., ... Howard, M. E. (2016). The utility of automated measures of ocular metrics for detecting driver drowsiness during extended wakefulness. Accident Analysis \& Prevention, 87, 127-133. https://doi.org/10.1016/j.aap.2015.11.033

Jackson, M. L., \& Van Dongen, H. P. A. (2011). Cognitive effects of sleepiness. In M. J. Thorpy $\&$ M. Billiard (Eds.), Sleepiness (pp. 72-81). Cambridge, UK: Cambridge University Press.

Jongkees, B. J., \& Colzato, L. S. (2016). Spontaneous eye blink rate as predictor of dopaminerelated cognitive function-A review. Neuroscience \& Biobehavioral Reviews, 71, 58-82. https://doi.org/10.1016/j.neubiorev.2016.08.020

Joshi, S., Li, Y., Kalwani, R. M., \& Gold, J. I. (2016). Relationships between Pupil Diameter and Neuronal Activity in the Locus Coeruleus, Colliculi, and Cingulate Cortex. Neuron, 89(1), 221-234. https://doi.org/10.1016/j.neuron.2015.11.028

Jouvet, M. (1969). Biogenic Amines and the States of Sleep. Science, 163(3862), 32-41. https://doi.org/10.1126/science.163.3862.32

Kaida, K., Akerstedt, T., Kecklund, G., Nilsson, J. P., \& Axelsson, J. (2007). The effects of asking for verbal ratings of sleepiness on sleepiness and its masking effects on performance. Clinical Neurophysiology, 118(6), 1324-1331. https://doi.org/10.1016/j.clinph.2007.03.004 
Kaida, K., Takahashi, M., Akerstedt, T., Nakata, A., Otsuka, Y., Haratani, T., \& Fukasawa, K. (2006). Validation of the Karolinska sleepiness scale against performance and EEG variables. Clinical Neurophysiology, 117(7), 1574-1581. https://doi.org/10.1016/j.clinph.2006.03.011

Kane, M. J., Brown, L. H., McVay, J. C., Silvia, P. J., Myin-Germeys, I., \& Kwapil, T. R. (2007). For whom the mind wanders, and when: An experience-sampling study of working memory and executive control in daily life. Psychological Science, 18(7), 614-621. https://doi.org/10.1111/j.1467-9280.2007.01948.x

Kane, M. J., Gross, G. M., Chun, C. A., Smeekens, B. A., Meier, M. E., Silvia, P. J., \& Kwapil, T. R. (2017). For Whom the Mind Wanders, and When, Varies Across Laboratory and DailyLife Settings. Psychological Science, 28(9), 1271-1289. https://doi.org/10.1177/0956797617706086

Killingsworth, M. A., \& Gilbert, D. T. (2010). A wandering mind is an unhappy mind. Science, 330(6006), 932. https://doi.org/10.1126/science.1192439

Koller, M. (2016). robustlmm: An R Package for Robust Estimation of Linear Mixed-Effects Models. Journal of Statistical Software, 75(1), 1-24.

Konishi, M., Brown, K., Battaglini, L., \& Smallwood, J. (2017). When attention wanders: Pupillometric signatures of fluctuations in external attention. Cognition, 168, 16-26. https://doi.org/10.1016/j.cognition.2017.06.006

Körber, M., Cingel, A., Zimmermann, M., \& Bengler, K. (2015). Vigilance Decrement and Passive Fatigue Caused by Monotony in Automated Driving. Procedia Manufacturing, 3, 24032409. https://doi.org/10.1016/j.promfg.2015.07.499

Krasich, K., McManus, R., Hutt, S., Faber, M., D’Mello, S. K., \& Brockmole, J. R. (2018). Gazebased signatures of mind wandering during real-world scene processing. Journal of Experimental Psychology: General, 147(8), 111-1124. https://doi.org/10.1037/xge0000411

Krause, A. J., Simon, E. B., Mander, B. A., Greer, S. M., Saletin, J. M., Goldstein-Piekarski, A. N., \& Walker, M. P. (2017). The sleep-deprived human brain. Nature Reviews Neuroscience, 18(7), 404-418. https://doi.org/10.1038/nrn.2017.55 
Larsen, R. S., \& Waters, J. (2018). Neuromodulatory Correlates of Pupil Dilation. Frontiers in Neural Circuits, 12. https://doi.org/10.3389/fncir.2018.00021

Larue, G. S., Rakotonirainy, A., \& Pettitt, A. N. (2010). Real-time performance modelling of a Sustained Attention to Response Task. Ergonomics, 53(10), 1205-1216. (20865604).

Lean, Y., \& Shan, F. (2012). Brief review on physiological and biochemical evaluations of human mental workload. Human Factors and Ergonomics in Manufacturing \& Service Industries, 22(3), 177-187. https://doi.org/10.1002/hfm.20269

Lemercier, C., Pêcher, C., Berthié, G., Valéry, B., Vidal, V., Paubel, P.-V., ... Maury, B. (2014). Inattention behind the wheel: How factual internal thoughts impact attentional control while driving. Safety Science, 62, 279-285.

Lim, J., \& Dinges, D. F. (2008). Sleep deprivation and vigilant attention. Annals of the New York Academy of Sciences, 1129, 305-322. https://doi.org/10.1196/annals.1417.002

Lindquist, S. I., \& McLean, J. P. (2011). Daydreaming and its correlates in an educational environment. Learning and Individual Differences, 21, 158-167. https://doi.org/10.1016/j.lindif.2010.12.006

Lund, H. G., Reider, B. D., Whiting, A. B., \& Prichard, J. R. (2010). Sleep patterns and predictors of disturbed sleep in a large population of college students. Journal of Adolescent Health, 46(2), 124-132. https://doi.org/10.1016/j.jadohealth.2009.06.016

Lustig, C., Hasher, L., \& Tonev, S. T. (2001). Inhibitory control over the present and the past. European Journal of Cognitive Psychology, 13(1-2), 107-122. https://doi.org/10.1080/09541440042000241

MacLean, A. W., Davies, D. R., \& Thiele, K. (2003). The hazards and prevention of driving while sleepy. Sleep Medicine Reviews, 7(6), 507-521. https://doi.org/10.1016/S1087_ 0792(03)90004-9

Maffei, A., \& Angrilli, A. (2018). Spontaneous eye blink rate: An index of dopaminergic component of sustained attention and fatigue. International Journal of Psychophysiology, 123, 58-63. https://doi.org/10.1016/j.ijpsycho.2017.11.009 
Martinon, L. M., Smallwood, J., McGann, D., Hamilton, C., \& Riby, L. M. (2019). The disentanglement of the neural and experiential complexity of self-generated thoughts: A users guide to combining experience sampling with neuroimaging data. NeuroImage, 192, 15-25. https://doi.org/10.1016/j.neuroimage.2019.02.034

Mathot, S. (2018). Pupillometry: Psychology, Physiology, and Function. Journal of Cognition, l(1), 16. https://doi.org/10.5334/joc.18

McVay, J. C., \& Kane, M. J. (2009). Conducting the train of thought: Working memory capacity, goal neglect, and mind wandering in an executive-control task. Journal of Experimental Psychology. Learning, Memory, and Cognition, 35(1), 196-204. https://doi.org/10.1037/a0014104

McVay, J. C., \& Kane, M. J. (2012). Drifting from slow to “d'oh!”: Working memory capacity and mind wandering predict extreme reaction times and executive control errors. Journal of Experimental Psychology: Learning, Memory, \& Cognition, 38(3), 525-549. https://doi.org/10.1037/a0025896

McVay, J. C., Kane, M. J., \& Kwapil, T. R. (2009). Tracking the train of thought from the laboratory into everyday life: an experience-sampling study of mind wandering across controlled and ecological contexts. Psychonomic Bulletin \& Review, 16(5), 857-863. https://doi.org/10.3758/PBR.16.5.857

Medea, B., Karapanagiotidis, T., Konishi, M., Ottaviani, C., Margulies, D., Bernasconi, A., ... Smallwood, J. (2018). How do we decide what to do? Resting-state connectivity patterns and components of self-generated thought linked to the development of more concrete personal goals. Experimental Brain Research, 236(9), 2469-2481. https://doi.org/10.1007/s00221-016-4729-y

Mikulincer, M., Babkoff, H., Caspy, T., \& Weiss, H. (1990). The impact of cognitive interference on performance during prolonged sleep loss. Psychological Research, 52(1), 80-86. Retrieved from MEDLINE. (2377728)

Mirman, D. (2014). Growth Curve Analysis and Visualization Using $R$. https://doi.org/10.1201/9781315373218 
Mittner, M., Boekel, W., Tucker, A. M., Turner, B. M., Heathcote, A., \& Forstmann, B. U. (2014). When the brain takes a break: a model-based analysis of mind wandering. Journal of Neuroscience, 34(49), 16286-16295. https://doi.org/10.1523/JNEUROSCI.2062-14.2014

Mooneyham, B. W., \& Schooler, J. W. (2013). The costs and benefits of mind-wandering: A review. Canadian Journal of Experimental Psychology / Revue Canadienne de Psychologie Expérimentale, 67(1), 11-18. Retrieved from PsycINFO.

Mrazek, M. D., Franklin, M. S., Phillips, D. T., Baird, B., \& Schooler, J. W. (2013). Mindfulness Training Improves Working Memory Capacity and GRE Performance While Reducing Mind Wandering. Psychological Science, 24(5), 776-781. https://doi.org/10.1177/0956797612459659

Müller, J., Dreisbach, G., Brocke, B., Lesch, K.-P., Strobel, A., \& Goschke, T. (2007). Dopamine and cognitive control: The influence of spontaneous eyeblink rate, DRD4 exon III polymorphism and gender on flexibility in set-shifting. Brain Research, 1131, 155-162. https://doi.org/10.1016/j.brainres.2006.11.002

Murphy, P. R., O’Connell, R. G., O’Sullivan, M., Robertson, I. H., \& Balsters, J. H. (2014). Pupil diameter covaries with BOLD activity in human locus coeruleus. Human Brain Mapping, 35(8), 4140-4154. https://doi.org/10.1002/hbm.22466

Nakano, T., Yamamoto, Y., Kitajo, K., Takahashi, T., \& Kitazawa, S. (2009). Synchronization of spontaneous eyeblinks while viewing video stories. Proceedings of the Royal Society B: Biological Sciences, 276(1673), 3635-3644. https://doi.org/10.1098/rspb.2009.0828

Ottaviani, C., \& Couyoumdjian, A. (2013). Pros and cons of a wandering mind: a prospective study. Frontiers in Psychology, 4, 524. https://doi.org/10.3389/fpsyg.2013.00524

Pepin, G., Malin, S., Jallais, C., Moreau, F., Fort, A., Navarro, J., ... Gabaude, C. (2018). Do distinct mind wandering differently disrupt drivers? Interpretation of physiological and behavioral pattern with a data triangulation method. Consciousness and Cognition, 62, 6981. https://doi.org/10.1016/j.concog.2018.04.006

Poh, J. H., Chong, P. L., \& Chee, M. W. (2016). Sleepless night, restless mind: Effects of sleep deprivation on mind wandering. Journal of Experimental Psychology: General, 145(10), 1312-1318. Retrieved from MEDLINE. (27359128) 
Qu, W., Ge, Y., Xiong, Y., Carciofo, R., Zhao, W., \& Zhang, K. (2015). The relationship between mind wandering and dangerous driving behavior among Chinese drivers. Safety Science, 78, 41-48. https://doi.org/10.1016/j.ssci.2015.04.016

Randall, J. G., Oswald, F. L., \& Beier, M. E. (2014). Mind-wandering, cognition, and performance: a theory-driven meta-analysis of attention regulation. Psychological Bulletin, 140(6), 1411-1431. https://doi.org/10.1037/a0037428

Reason, J. T. (1984). Lapses of attention in everyday life. In R. Parasuraman \& D. R. Davies (Eds.), Varieties of attention. Orlando: Academic Press.

Revelle, W. (2018). psych: Procedures for Psychological, Psychometric, and PersonalityResearch. Northwestern University, Evanston, Illinois. R package version 1.8.12. Retrieved from https://CRAN.R-project.org/package=psych

Robbins, T. W., \& Arnsten, A. F. T. (2009). The Neuropsychopharmacology of Fronto-Executive Function: Monoaminergic Modulation. Annual Review of Neuroscience, 32(1), 267-287. https://doi.org/10.1146/annurev.neuro.051508.135535

Robertson, I. H., Manly, T., Andrade, J., Baddeley, B. T., \& Yiend, J. (1997). “Oops!”: performance correlates of everyday attentional failures in traumatic brain injured and normal subjects. Neuropsychologia, 35(6), 747-758. https://doi.org/10.1016/S00283932(97)00015-8

Robison, M. K., Miller, A. L., \& Unsworth, N. (2019). Examining the effects of probe frequency, response options, and framing within the thought-probe method. Behavior Research Methods, 51(1), 398-408. https://doi.org/10.3758/s13428-019-01212-6

Rost, M., Zilberg, E., Xu, Z. M., Feng, Y., Burton, D., \& Lal, S. (2015). Comparing Contribution of Algorithm Based Physiological Indicators for Characterisation of Driver Drowsiness. Journal of Medical and Bioengineering, 4(5), 391-398. https://doi.org/10.12720/jomb.4.5.391-398

Salvi, C., \& Bowden, E. M. (2016). Looking for Creativity: Where Do We Look When We Look for New Ideas? Frontiers in Psychology, 7. https://doi.org/10.3389/fpsyg.2016.00161 
Salvi, C., Bricolo, E., Franconeri, S. L., Kounios, J., \& Beeman, M. (2015). Sudden insight is associated with shutting out visual inputs. Psychonomic Bulletin \& Review, 22(6), 18141819. https://doi.org/10.3758/s13423-015-0845-0

Samuels, E. R., \& Szabadi, E. (2008). Functional neuroanatomy of the noradrenergic locus coeruleus: its roles in the regulation of arousal and autonomic function part I: principles of functional organisation. Current Neuropharmacology, 6(3), 235-253. https://doi.org/10.2174/157015908785777229

Schleicher, R., Galley, N., Briest, S., \& Galley, L. (2008). Blinks and saccades as indicators of fatigue in sleepiness warnings: looking tired? Ergonomics, 51(7), 982-1010. https://doi.org/10.1080/00140130701817062

Schneider, F., Bermpohl, F., Heinzel, A., Rotte, M., Walter, M., Tempelmann, C., ... Northoff, G. (2008). The resting brain and our self: self-relatedness modulates resting state neural activity in cortical midline structures. Neuroscience, 157(1), 120-131. (18793699).

Schooler, J. W., Smallwood, J., Christoff, K., Handy, T. C., Reichle, E. D., \& Sayette, M. A. (2011). Meta-awareness, perceptual decoupling and the wandering mind. Trends in Cognitive Sciences, 15(7), 319-326. https://doi.org/10.1016/j.tics.2011.05.006

Schwarz, J., Gerhardsson, A., Lekander, M., Fischer, H., Axelsson, J., Kecklund, G., \& Åkerstedt, T. (2017). Age-dependent effects of sleep deprivation on task performance and mind wandering. Sleep Medicine, 40, e297. https://doi.org/10.1016/j.sleep.2017.11.873

Shaw, T. H., Matthews, G., Warm, J. S., Finomore, V. S., Silverman, L., \& Costa, P. T. (2010). Individual differences in vigilance: Personality, ability and states of stress. Journal of Research in Personality, 44(3), 297-308. https://doi.org/10.1016/j.jrp.2010.02.007

Short, M. A., \& Banks, S. (2014). The functional impact of sleep deprivation, sleep restriction, and sleep fragmentation. In M. T. Bianchi (Ed.), Sleep deprivation and disease: Effects on the body, brain and behavior (pp. 13-26). https://doi.org/10.1007/978-1-4614-9087-6_2

Simmons, J. P., Nelson, L. D., \& Simonsohn, U. (2011). False-positive psychology: undisclosed flexibility in data collection and analysis allows presenting anything as significant. Psychological Science, 22(11), 1359-1366. https://doi.org/10.1177/0956797611417632 
Smallwood, J. (2013). Distinguishing how from why the mind wanders: A process-occurrence framework for self-generated mental activity. Psychological Bulletin, 139(3), 519-535. https://doi.org/10.1037/a0030010

Smallwood, J., Brown, K. S., Baird, B., Mrazek, M. D., Franklin, M. S., \& Schooler, J. W. (2012). Insulation for daydreams: a role for tonic norepinephrine in the facilitation of internally guided thought. PLoS ONE [Electronic Resource], 7(4), e33706. (22493672).

Smallwood, J., Brown, K. S., Tipper, C., Giesbrecht, B., Franklin, M. S., Mrazek, M. D., ... Schooler, J. W. (2011). Pupillometric evidence for the decoupling of attention from perceptual input during offline thought. PLOS ONE, 6(3), e18298. (21464969).

Smallwood, J., Davies, J. B., Heim, D., Finnigan, F., Sudberry, M., O’Connor, R., \& Obonsawin, M. (2004). Subjective experience and the attentional lapse: Task engagement and disengagement during sustained attention. Consciousness and Cognition: An International Journal, 13(4), 657-690. https://doi.org/10.1016/j.concog.2004.06.003

Smallwood, J., \& Schooler, J. W. (2006). The restless mind. Psychological Bulletin, 132(6), 946958. https://doi.org/10.1037/0033-2909.132.6.946

Smallwood, J., \& Schooler, J. W. (2015). The science of mind wandering: empirically navigating the stream of consciousness. Annual Review of Psychology, 66, 487-518. https://doi.org/10.1146/annurev-psych-010814-015331

Smilek, D., Carriere, J. S., \& Cheyne, J. (2010a). Failures of sustained attention in life, lab, and brain: Ecological validity of the SART. Neuropsychologia, 48(9), 2564-2570. https://doi.org/10.1016/j.neuropsychologia.2010.05.002

Smilek, D., Carriere, J. S., \& Cheyne, J. (2010b). Out of mind, out of sight: Eye blinking as indicator and embodiment of mind wandering. Psychological Science, 21(6), 786-789. (Peer Reviewed Journal: 2010-13268-005).

Spreng, R. N., Stevens, W. D., Chamberlain, J. P., Gilmore, A. W., \& Schacter, D. L. (2010). Default network activity, coupled with the frontoparietal control network, supports goaldirected cognition. Neuroimage, 53(1), 303-317. (20600998). 
Stawarczyk, D. (2018). Phenomenological Properties of Mind-Wandering and Daydreaming: A Historical Overview and Functional Correlates. In K. R. C. Fox \& K. Christoff (Eds.), The Oxford Handbook of Spontaneous Thought (pp. 193-214). New York: Oxford University Press.

Stawarczyk, D., Cassol, H., \& D’Argembeau, A. (2013). Phenomenology of future-oriented mind$\begin{array}{lllll}\text { wandering } & \text { episodes. Frontiers in Psychology, 4, } 225 .\end{array}$ https://doi.org/10.3389/fpsyg.2013.00425

Stawarczyk, D., \& D’Argembeau, A. (2016). Conjoint influence of mind-wandering and sleepiness on task performance. Journal of Experimental Psychology: Human Perception \& Performance, 42(10), 1587-1600. https://doi.org/10.1037/xhp0000254

Stawarczyk, D., Majerus, S., Catale, C., \& D’Argembeau, A. (2014). Relationships between mindwandering and attentional control abilities in young adults and adolescents. Acta Psychologica, 148, 25-36. https://doi.org/10.1016/j.actpsy.2014.01.007

Stawarczyk, D., Majerus, S., Maj, M., Van der Linden, M., \& D’Argembeau, A. (2011). Mindwandering: phenomenology and function as assessed with a novel experience sampling method. Acta Psychologica, 370-381. https://doi.org/10.1016/j.actpsy.2011.01.002

Szabadi, E. (2013). Functional neuroanatomy of the central noradrenergic system. Journal of Psychopharmacology, 27(8), 659-693. https://doi.org/10.1177/0269881113490326

Taylor, D. J., Bramoweth, A. D., Grieser, E. A., Tatum, J. I., \& Roane, B. M. (2013). Epidemiology of insomnia in college students: relationship with mental health, quality of life, and substance use difficulties. Behavior Therapy, 44(3), 339-348. https://doi.org/10.1016/j.beth.2012.12.001

Tharp, I. J., \& Pickering, A. D. (2011). Individual differences in cognitive-flexibility: The influence of spontaneous eyeblink rate, trait psychoticism and working memory on attentional set-shifting. Brain and Cognition, 75(2), 119-125. https://doi.org/10.1016/j.bandc.2010.10.010 
Unsworth, N., Brewer, G. A., \& Spillers, G. J. (2012). Variation in cognitive failures: An individual differences investigation of everyday attention and memory failures. Journal of Memory and Language, 67(1), 1-16. https://doi.org/10.1016/j.jml.2011.12.005

Unsworth, N., \& McMillan, B. D. (2014). Similarities and differences between mind-wandering and external distraction: a latent variable analysis of lapses of attention and their relation to cognitive abilities. Acta Psychologica, 150, 14-25. https://doi.org/10.1016/j.actpsy.2014.04.001

Unsworth, N., McMillan, B. D., Brewer, G. A., \& Spillers, G. J. (2012). Everyday attention failures: An individual differences investigation. Journal of Experimental Psychology: Learning, Memory, and Cognition, 38(6), 1765-1772. https://doi.org/10.1037/a0028075

Unsworth, N., \& Robison, M. K. (2016). Pupillary correlates of lapses of sustained attention. Cognitive, Affective \& Behavioral Neuroscience, 1, 1. https://doi.org/10.3758/s13415-016$0417-4$

Unsworth, N., \& Robison, M. K. (2017). A locus coeruleus-norepinephrine account of individual differences in working memory capacity and attention control. Psychonomic Bulletin \& Review, 24(4), 1282-1311. https://doi.org/10.3758/s13423-016-1220-5

Unsworth, N., \& Robison, M. K. (2018). Tracking arousal state and mind wandering with pupillometry. Cognitive, Affective, \& Behavioral Neuroscience, 18(4), 638-664. https://doi.org/10.3758/s13415-018-0594-4

Unsworth, N., Robison, M. K., \& Miller, A. L. (2018). Pupillary Correlates of Fluctuations in Sustained Attention. Journal of Cognitive Neuroscience, 30(9), 1241-1253. https://doi.org/10.1162/jocn_a_01251

van den Brink, R. L., Murphy, P. R., \& Nieuwenhuis, S. (2016). Pupil Diameter Tracks Lapses of Attention. PLOS ONE, 11(10), e0165274. https://doi.org/10.1371/journal.pone.0165274

van der Wel, P., \& van Steenbergen, H. (2018). Pupil dilation as an index of effort in cognitive control tasks: A review. Psychonomic Bulletin \& Review, 25(6), 2005-2015. https://doi.org/10.3758/s13423-018-1432-y 
Vincent, J. L., Kahn, I., Snyder, A. Z., Raichle, M. E., \& Buckner, R. L. (2008). Evidence for a frontoparietal control system revealed by intrinsic functional connectivity. Journal of Neurophysiology, 100(6), 3328-3342. (18799601).

Volkow, N. D., Tomasi, D., Wang, G.-J., Telang, F., Fowler, J. S., Wang, R. L., ... Swanson, J. M. (2009). Hyperstimulation of striatal D2 receptors with sleep deprivation: Implications for cognitive impairment. NeuroImage, 45(4), 1232-1240. https://doi.org/10.1016/j.neuroimage.2009.01.003

Walcher, S., Körner, C., \& Benedek, M. (2017). Looking for ideas: Eye behavior during goaldirected internally focused cognition. Consciousness and Cognition, 53, 165-175. https://doi.org/10.1016/j.concog.2017.06.009

Walker, H. E. K., \& Trick, L. M. (2018). Mind-wandering while driving: The impact of fatigue, task length, and sustained attention abilities. Transportation Research Part F: Traffic Psychology and Behaviour, 59, 81-97. https://doi.org/10.1016/j.trf.2018.08.009

Wammes, J. D., Seli, P., Cheyne, J. A., Boucher, P. O., \& Smilek, D. (2016). Mind Wandering During Lectures II: Relation to Academic Performance. Scholarship of Teaching and Learning in Psychology, 2(1), 33-48. Retrieved from Journals@.

Ward, A. F., \& Wegner, D. M. (2013). Mind-blanking: when the mind goes away. Frontiers in Psychology, 4, 650. https://doi.org/10.3389/fpsyg.2013.00650

Warm, J. S. (1984). Sustained attention in human performance. Chichester, U. K.: Wiley.

Weinstein, Y. (2018). Mind-wandering, how do I measure thee with probes? Let me count the ways. Behavior Research Methods, 50(2), 642-661. https://doi.org/10.3758/s13428-0170891-9

Yanko, M. R., \& Spalek, T. M. (2014). Driving with the wandering mind: the effect that mindwandering has on driving performance. Human Factors, 56(2), 260-269. https://doi.org/10.1177/0018720813495280

Zhao, Y., Lofi, C., \& Hauff, C. (2017). Scalable Mind-Wandering Detection for MOOCs: A Webcam-Based Approach. In E. Lavoué, H. Drachsler, K. Verbert, J. Broisin, \& M. Pérez- 
Sanagustín (Eds.), Data Driven Approaches in Digital Education (pp. 330-344). Springer International Publishing. 


\section{Figures}

a.

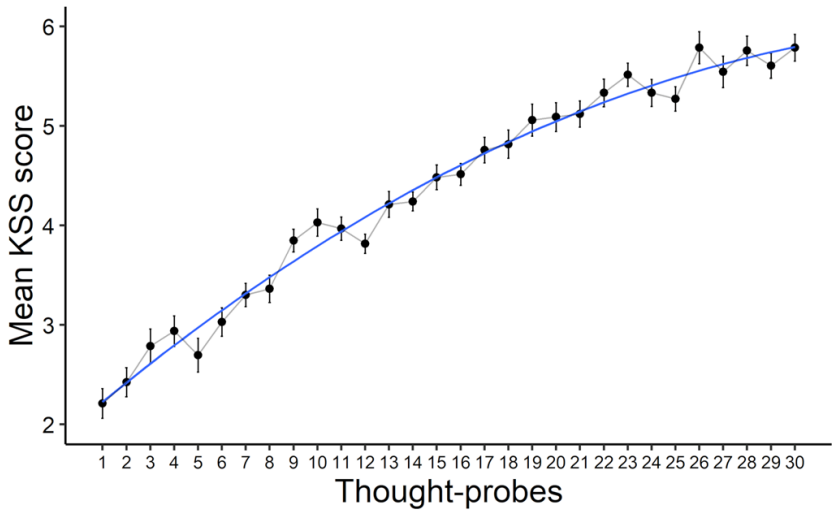

b.

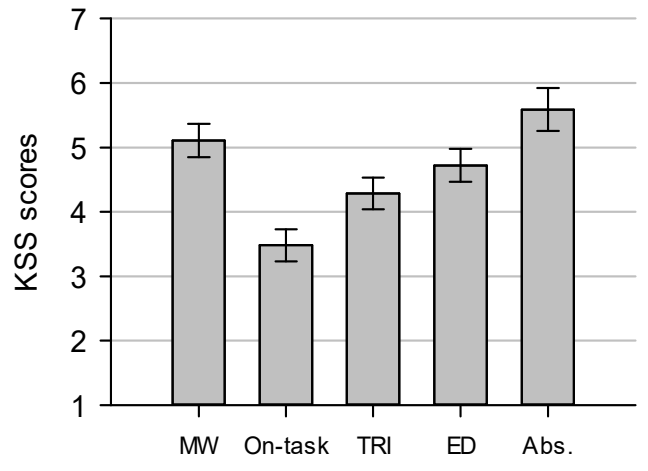

Figure 1. Panel a. illustrates the variation in the mean KSS scores with time on task and the fitted quadratic curve. Error bars represent the standard error of the mean. Panel b. illustrates the KSS scores and standard errors estimated from the linear mixed model with the thought-probe responses as fixed effect of interest. KSS = Karolinska Sleepiness Scale TRI = task-related interference; ED $=$ external distraction; $\mathrm{MW}=$ mind-wandering; Abs. $=$ absence. 
a.

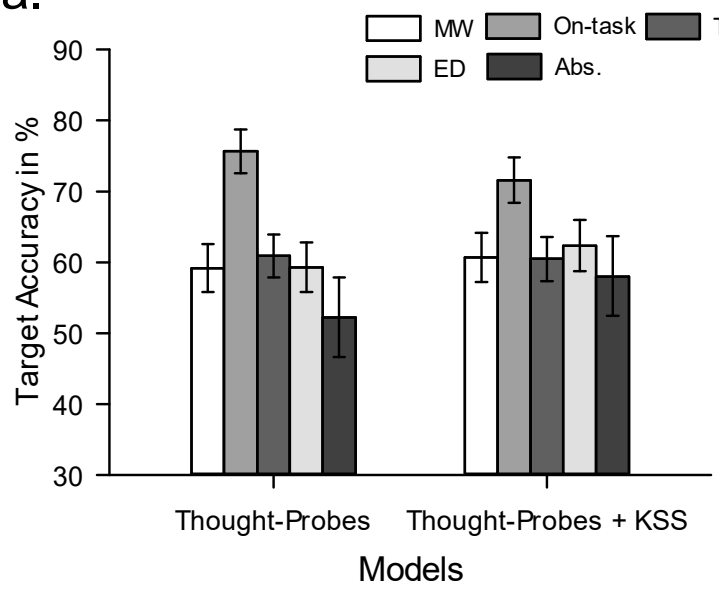

C.

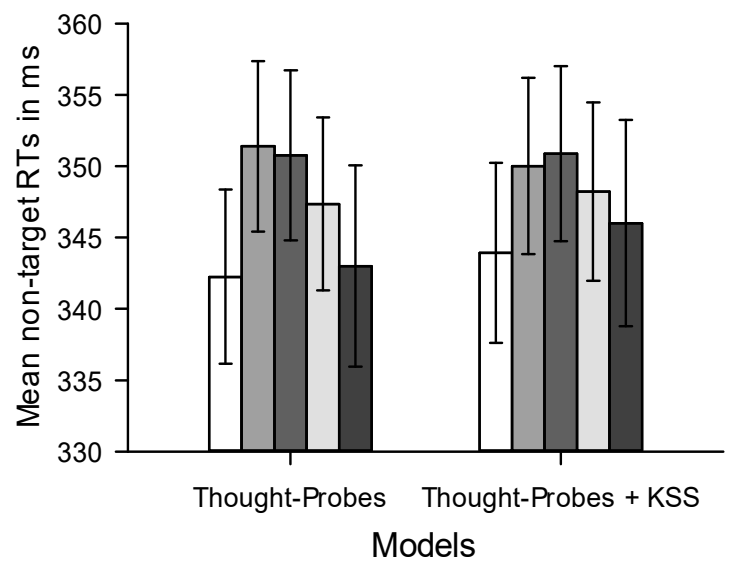

b.

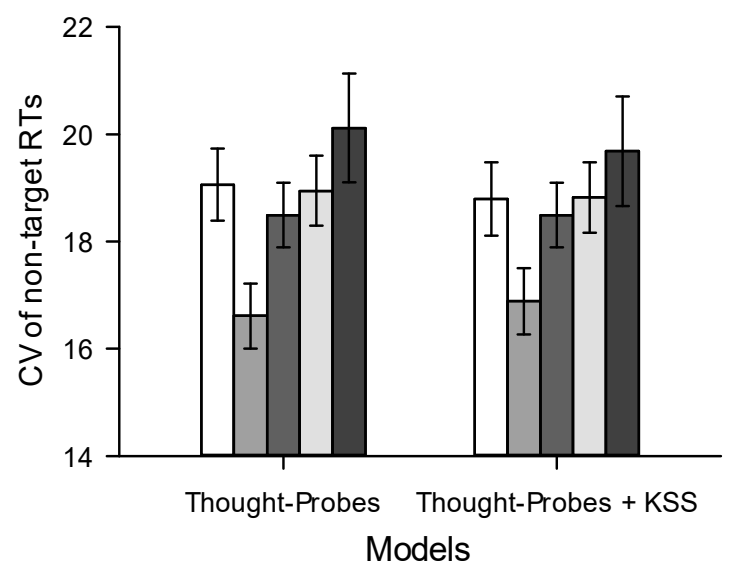

Figure 2. Differences in mean target accuracy (panel a), coefficient of variation of RTs to nontargets (panel b), and mean RTs to non-targets (panel c) as a function of thought-probe responses. The mean values and standard errors are estimated from the linear mixed models with thoughtsprobe responses only (left) or with both thought-probe responses and KSS scores as fixed effects of interest (right). $\mathrm{RT}=$ response time; $\mathrm{CV}=$ coefficient of variation; $\mathrm{KSS}=$ Karolinska Sleepiness Scale $\mathrm{TRI}=$ task-related interference; $\mathrm{ED}=$ external distraction; $\mathrm{MW}=$ mind-wandering; $\mathrm{Abs} .=$ absence. 

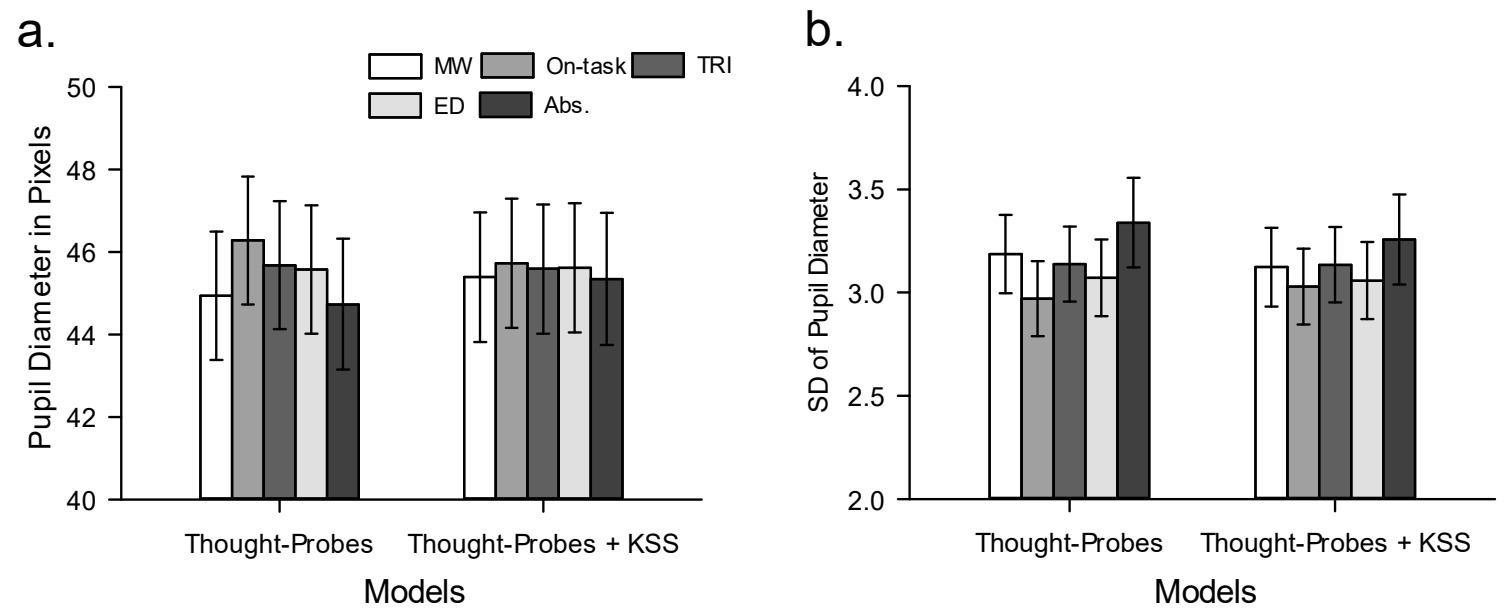

Figure 3. Differences in mean pupil diameter (panel a) and standard deviation of pupil diameter (panel b) as a function of thought-probe responses. The mean values and standard errors are estimated from the linear mixed models with thoughts-probe responses only (left) or with both thought-probe responses and KSS scores as fixed effects of interest (right). SD $=$ standard deviation; KSS $=$ Karolinska Sleepiness Scale TRI $=$ task-related interference; ED $=$ external distraction; $\mathrm{MW}=$ mind-wandering; Abs. $=$ absence . 


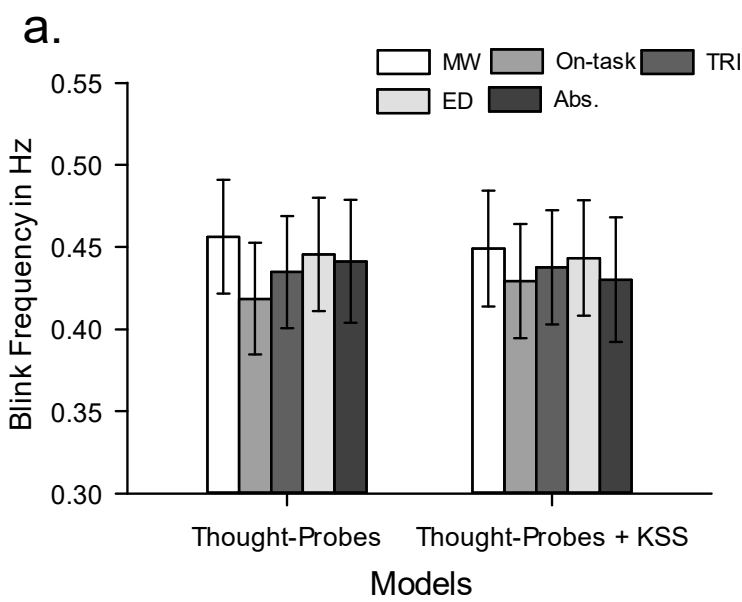

b.

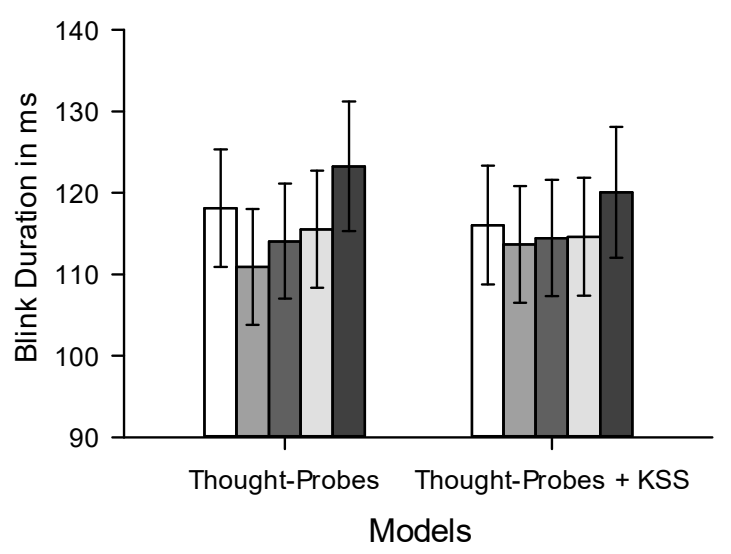

Figure 4. Differences in blink frequency (panel a) and blink duration (panel b) as a function of thought-probe responses. The mean values and standard errors are estimated from the linear mixed models with thoughts-probe responses only (left) or with both thought-probe responses and KSS scores as fixed effects of interest (right). KSS $=$ Karolinska Sleepiness Scale TRI $=$ task-related interference; $\mathrm{ED}=$ external distraction; $\mathrm{MW}=$ mind-wandering; Abs. $=$ absence. 